\title{
Light based underwater wireless communications
}

Hassan M. Oubei ${ }^{1}$, Chao Shen ${ }^{1}$, Abla Kammoun ${ }^{2}$, Emna Zedini ${ }^{2}$, Ki-Hong Park ${ }^{2}$, Xiaobin Sun ${ }^{1}$, Guangyu Liu ${ }^{1}$, Chun Hong Kang ${ }^{1}$, Tien Khee $\mathrm{Ng}^{1}$, Mohamed-Slim Alouini ${ }^{2}$, and Boon S. Ooi ${ }^{1 *}$

${ }^{1}$ Photonics Laboratory, King Abdullah University of Science and Technology (KAUST), Thuwal 23955-6900, Saudi Arabia.

${ }^{2}$ Communication Theory Laboratory, King Abdullah University of Science and Technology (KAUST), Thuwal 23955-6900, Saudi Arabia.

*E-mail: boon.ooi@kaust.edu.sa

Underwater wireless optical communication (UWOC) is a wireless communication technology that uses visible light to transmit data in underwater environment. Compared to radio-frequency (RF) and acoustic underwater techniques, UWOC has many advantages including large information bandwidth, unlicensed spectrum and low power requirements. This review paper provides an overview of the latest UWOC research. Additionally, we present a detailed description of transmitter and receiver technologies which are key components of UWOC systems. Moreover, studies investigating underwater optical channel models for both simple attenuation and the impact of turbulence including air bubbles and inhomogeneous salinity and temperature are also described. Future research challenges are identified and outlined. 


\section{Introduction}

More than $70 \%$ of earth's surface is covered by water and today world oceans are critically indispensable in all aspects of life on earth from food to the air and from mineral resources to climate change. In recent years, human activities in underwater have significantly increased and there is an urgent need to demonstrate highly reliable, secured and high data rate underwater wireless communication (UWC) systems. Such systems have practical applications such as realtime video transmission, monitoring of offshore floating oil production platforms, military submarine communications, and environmental surveying and monitoring.

Classically, acoustics communication is the most dominant technique for underwater wireless links achieving a long link distance up to tens of kilometers. ${ }^{1,2)}$ However, underwater acoustics is limited to low frequencies $(10 \mathrm{~Hz}-1 \mathrm{MHz})$ that compromise the system bandwidth and subsequently limiting the transmission data rate to low values on the order of kbps. ${ }^{3}$ Other limitations of underwater acoustics include high latency due to slow propagation of sound waves in seawater $(\approx 1500 \mathrm{~m} / \mathrm{s})$, time varying multipath propagation, Doppler spread, and bulky and power hungry transceiver modules. ${ }^{2)}$ Radio frequency (RF) is another technology that can provide tens of Mbps data rate in underwater but it is limited to very short link ranges (few meters) due to high conductivity of seawater that highly attenuates $R F$ waves. ${ }^{4-7)}$ In addition, underwater RF systems come with huge antennas, high energy consumption, and high cost. The third method to communicate in underwater is the fiber optics technology which provides long link ranges at transmission data rate up to giga-bit-per-second (Gbps). The drawback of fiber optics based systems is that both the transmitter and receiver have to be physically connected via a cable which is undesirable for many tactical applications such as autonomous underwater vehicles (AUV).

Light based underwater wireless communication also known as underwater visible light communication (UVLC) or underwater wireless optical communication (UWOC) in the research community has been proposed as an alternative or complementary solution to acoustics and RF technologies. ${ }^{4,89}$ Taking advantages of the low absorption window of seawater in visible portion of the electromagnetic (EM) spectrum, UWOC provides unprecedentedly high transmission data rate thanks to the large available bandwidth (THz). ${ }^{10,11)}$ Link distances up to hundreds of meters $(\approx 300 \mathrm{~m})$ are possible. Other advantages of UWOC include high security, low power requirements, and unlicensed spectrum. Figure 1 presents various underwater platforms such as ships, sensors, divers and submarines that might benefit from the high bandwidth light based 
underwater wireless communication systems. Despite being a new field of research, UWOC has seen significant progress in the last few years facilitated by the recent wide technological advances in visible light emitters, receivers, digital communications and signal processing. ${ }^{12,13)}$ From system level demonstrations to channel modeling, UWOC is quickly becoming a mature technology. This review paper builds on the works of M. Khaligi et al. ${ }^{14)}$ and Z. Zeng et al. ${ }^{15)}$. The rest of this manuscript is organized as follows. In Section 2, a brief overview of light based underwater communications is put forth while Section 3 presents the UWOC system. A detailed insight on the latest development of transmitter and receiver technologies already adopted in UWOC demonstrations or potentially viable for future adoption in UWOC is provided. In Section 4, we discuss the UWOC channel models. Section 5 outlines the future challenges of UWOC research. Conclusions are drawn in Section 6.

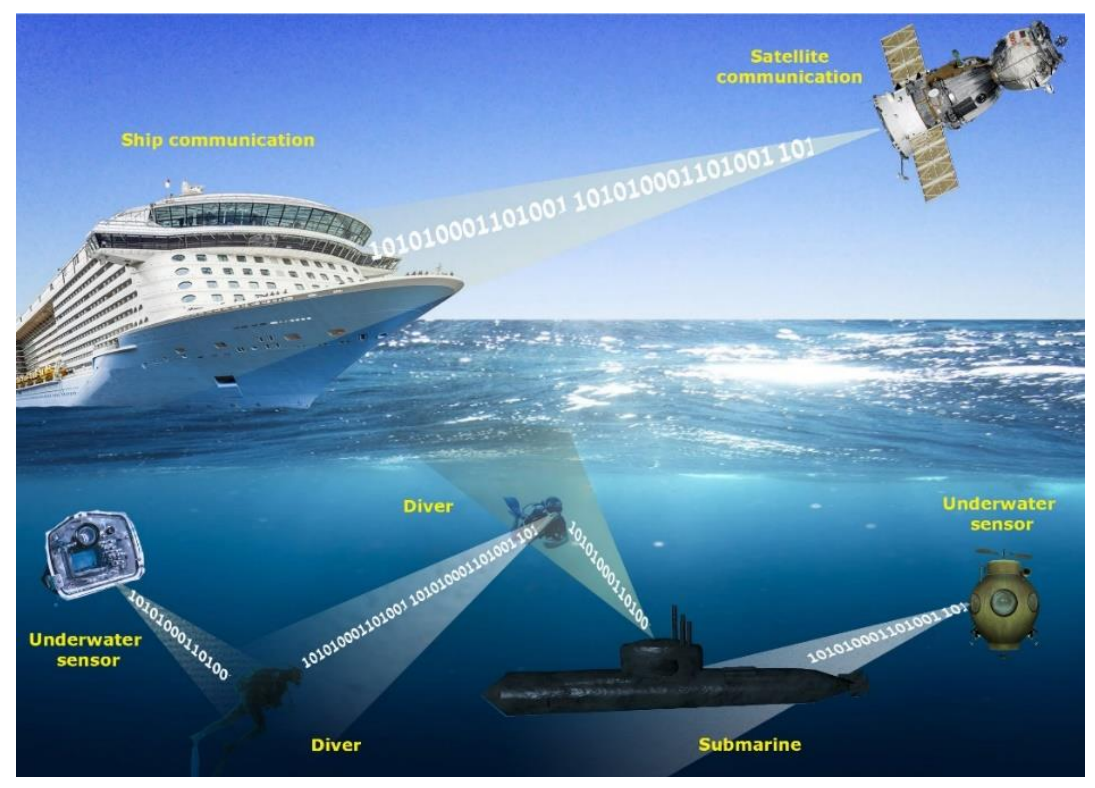

Fig. 1. (Color online) Illustration of various underwater platforms requiring reliable and high speed wireless links.

\section{Overview of light based underwater communications}

\subsection{Progress in light based underwater wireless communications}

Light based underwater communication links have been investigated since 1970's, ${ }^{16)}$ with Karp characterizing the channel between underwater and satellite terminals using multiple scattering model. ${ }^{17)}$ In 1992, Snow et al. ${ }^{18)}$ have experimentally demonstrated a 50 Mbps laser (argon-ion $(\mathrm{Ar}+) 514 \mathrm{~nm}$ ) link over $5.1 \mathrm{~m}$ attenuation lengths in a highly absorbing but low scattering water. 
The first gigabit underwater communication link was established by Hanson and Radic using an externally modulated and frequency doubled $532 \mathrm{~nm}$ laser beam. ${ }^{4)}$ A data rate of 1 Gbps over $2 \mathrm{~m}$ water tank was achieved. In 2005, Farr and co-workers established a $10 \mathrm{Mbps}, 91 \mathrm{~m}$ omnidirectional UWOC system using an array of commercially available $470 \mathrm{~nm}$ blue light emitting diodes (LEDs). ${ }^{19)}$ The same authors also demonstrated a full-duplex 10 Mbps real time video transmission system. ${ }^{20)}$ Laux et al. have validated the use of Maalox as scattering agent by measuring and comparing its volume scattering function against two different measurements in a $3 \mathrm{~m}$ laboratory water tank. ${ }^{21)}$ In addition, they also measured and verified small forward angle function for Maalox and validated with a Monte Carlo model with excellent agreement. Spatial effects of multiple scattering of a laser beam in underwater were investigated by Cochenour. ${ }^{22)}$ It was revealed that at higher attenuation lengths or higher turbidity levels, multiple scattering is significant and some of the scattered photons might enter back into the receiver field of view (FOV) which ultimately improve the overall non-temporal performance of the link. Polarization properties of both forward-scattered and backscattered light were studied by Mullen. ${ }^{23)}$ The polarization discrimination technique was utilized to suppress backscattered light in modulating retroreflector links. The same study also revealed that the forward-scattered light is partially polarized up to extremely high water turbidities.

Early works on UWOC channel models mostly focused on Monte Carlo model. Using a Monte Carlo simulation, Khalighi et al. presented a channel model that takes into account the type of water, and different transmitter and receiver characteristics. The channel delay spread was found to be negligible and can be modeled as frequency non-selective channel, except in very turbid waters. ${ }^{24)}$ William Cox developed a Monte Carlo numerical simulation of light propagating underwater and simulated power loss between transmitter and receiver for a variety of receiver aperture sizes and fields of view. ${ }^{25}$ ) The effects of both attenuation and optical turbulence on underwater imaging was the focus of a study conducted by Weilin Hou. ${ }^{26)}$ It was observed that turbulence in natural underwater environments can limit imaging resolution by affecting high spatial frequencies. UWOC networks were studied by Arnon et al. ${ }^{27,28)}$ High data rates network links for both line-of-sight (LOS) and non-line-of-sight (NLOS) configurations were found to be feasible for medium distances of up to $100 \mathrm{~m}$. The effects of different air bubble populations on the performance of UWOC links were investigated by Oubei et al. ${ }^{29)}$ Air bubbles were found to significantly deteriorate the quality of the received signal leading to performance degradation of 
the UWOC link. The authors proposed beam expansion as a potential technique to mitigate the performance degradation.

Recent researches in UWOC have mostly focused on system level demonstrations with particular emphasis placed on different modulation techniques to increase both the data transmission rate and the link distance. Oubei et al. have established a simple $2.3 \mathrm{Gbps}, 7 \mathrm{~m}$ directly modulated $520 \mathrm{~nm}$ laser diode (LD) communication system. ${ }^{30,31)}$ A more realistic $20 \mathrm{~m}$ outdoor pool underwater transmission at a data rate of $1.5 \mathrm{Gbps}$ has been achieved, using a 405 nm laser diode with On-Off Keying (OOK). ${ }^{32)}$ To achieve higher data rates and maximize the transmission capacity of UWOC systems, several experimental demonstrations of spectrally efficient orthogonal frequency division multiplexing (OFDM) modulation technique were carried out in the last few years. ${ }^{9,11,33-36)}$ Notably, T. C. Wu et al. have experimentally achieved a 12.4 Gbps 16-QAM OFDM data transmission over 1.7 m underwater link using a $450 \mathrm{~nm}$ laser diode. ${ }^{10)}$ Meanwhile, J. Xu has reported 2.0 m, 161 Mbps using $450 \mathrm{~nm}$ LED. ${ }^{37)}$ Such LED based UWOC systems can be more promising for applications that require medium bit rates, low cost, and simultaneous illumination and communication. Several researchers have also looked into orbital angular momentum (OAM) multiplexing, ${ }^{38,39)}$ multiple-input and multiple-output (MIMO) ${ }^{40,41)}$ and wavelength division multiplexing $(\mathrm{WDM})^{11)}$ to further increase the system data rate. Table I gives a brief summary of data rates and link distances achieved in recent UWOC system level demonstrations. ${ }^{9-11,32-34,38,42,43)}$

Table I. Summary of recently achieved UWOC data transmission rates and links distances

\begin{tabular}{|c|c|c|c|c|c|c|}
\hline Authors & $\begin{array}{c}\text { Modulation } \\
\text { Scheme }\end{array}$ & $\begin{array}{c}\text { Transmitter } \\
\text { Type }\end{array}$ & $\begin{array}{l}\text { Photo- } \\
\text { detector }\end{array}$ & $\begin{array}{c}\text { Transmitter } \\
\text { Power }\end{array}$ & $\begin{array}{l}\text { Link } \\
\text { Range }\end{array}$ & Data Rate \\
\hline $\begin{array}{l}\text { K. Nakamura }{ }^{9)} \\
\text { (Uni. of } \\
\text { Yamanashi) } \\
\text { (2015) }\end{array}$ & OFDM & $405 \mathrm{~nm} \mathrm{LD}$ & APD & $45 \mathrm{~mW}$ & $4.8 \mathrm{~m}$ & $1.45 \mathrm{Gbps}$ \\
\hline $\begin{array}{l}\text { J. Baghdady }{ }^{38)} \\
\text { (Clemson Uni.) } \\
\text { (2016) }\end{array}$ & OAM-OOK & $445 \mathrm{~nm} \mathrm{LD}$ & APD & $15 \mathrm{~mW}$ & $2.96 \mathrm{~m}$ & 3 Gbps \\
\hline $\begin{array}{l}\text { C. Shen }{ }^{32)} \\
\text { (KAUST) } \\
(\mathbf{2 0 1 6 )}\end{array}$ & OOK & $450 \mathrm{~nm} \mathrm{LD}$ & APD & $51.3 \mathrm{~mW}$ & $20 \mathrm{~m}$ & $1.5 \mathrm{Gbps}$ \\
\hline $\begin{array}{l}\text { Y. Huang }{ }^{42)} \\
\text { (National }\end{array}$ & OFDM & $450 \mathrm{~nm} \mathrm{LD}$ & PIN/APD & $120 \mathrm{~mW}$ & $1.7 \mathrm{~m}$ & $14.8 \mathrm{Gbps}$ \\
\hline
\end{tabular}




\begin{tabular}{|c|c|c|c|c|c|c|}
\hline $\begin{array}{l}\text { Taiwan Uni.) } \\
\text { (2018) }\end{array}$ & & & & & & \\
\hline $\begin{array}{l}\text { X. Liu'3) } \\
\text { (Fudan Uni.) } \\
(\mathbf{2 0 1 7})\end{array}$ & OOK & $520 \mathrm{~nm} \mathrm{LD}$ & APD & $19.4 \mathrm{~mW}$ & $34.5 \mathrm{~m}$ & $2.7 \mathrm{Gbps}$ \\
\hline $\begin{array}{l}\text { Y. Chen }{ }^{34)} \\
\text { (Zhejiang Uni.) } \\
\text { (2017) }\end{array}$ & OFDM & $520 \mathrm{~nm} \mathrm{LD}$ & APD & $15 \mathrm{~mW}$ & $21 \mathrm{~m}$ & $5.5 \mathrm{Gbps}$ \\
\hline $\begin{array}{l}\text { P. Tian } \\
\text { (Fudan Uni.) } \\
\text { (2017) }\end{array}$ & OOK & $\begin{array}{l}450 \mathrm{~nm} \mu- \\
\quad \text { LED }\end{array}$ & PIN/APD & $1.5 \mathrm{~mW}$ & $5.4 \mathrm{~m}$ & $200 \mathrm{Mbps}$ \\
\hline $\begin{array}{l}\text { T. C. } \mathrm{Wu}^{10)} \\
\text { (NTU) } \\
(\mathbf{2 0 1 7})\end{array}$ & OFDM & $450 \mathrm{~nm} \mathrm{LD}$ & PIN & $47 \mathrm{~mW}$ & $1.7 \mathrm{~m}$ & 12.4 Gbps \\
\hline $\begin{array}{l}\text { M. Kong }{ }^{11} \\
\text { (Zhejiang Uni.) } \\
\text { (2017) }\end{array}$ & OFDM & $\begin{array}{c}\text { RGB- } \\
\text { WDM LD }\end{array}$ & APD & $15 / 35 \mathrm{~mW}$ & $10 \mathrm{~m}$ & $9.51 \mathrm{Gbps}$ \\
\hline
\end{tabular}

Another aspect of recent UWOC research is the channel modeling taking into account the effects of optical turbulence using experimental measurements. The probability density functions of laser beam intensity fluctuations due to salty and bubbly underwater channels under various channel conditions were experimentally obtained by Jamali. ${ }^{44)}$ Weibull distribution was used to describe the statistics of salinity-induced turbulent UWOC channels. ${ }^{45)}$ The model showed an excellent fit with the measured data under all channel conditions emulated. In another study, ${ }^{46)}$ the authors have accurately developed a simple statistical channel model for weak temperatureinduced turbulence in UWOC systems. The generalized Gamma distribution (GGD) was found to perfectly describe both non-turbulent thermally uniform underwater optical channels and underwater optical channels with temperature gradients. A more comprehensive study to characterize turbulence-induced fading in UWOC channels in the presence of air bubbles for fresh and salty waters, based on experimental data was proposed by Zedini et al. ${ }^{47)}$ The mixture Exponential-Gamma distribution model was used to describe the channel irradiance fluctuations. The proposed model provided an excellent goodness of fit to the measured data under all the channel conditions for both types of water.

The application of both exponential-Gamma and generalized Gamma distribution models lead to closed-form and analytically tractable expressions which are plausibly beneficial to the design of UWOC systems and key link performance analysis such as the outage probability, the average 
bit-error rate, and the ergodic capacity. ${ }^{47)}$ The various system level demonstrations carried out over the years by different research groups coupled with the recent channel models pave the way for developing a comprehensive and unified model to predict the performance of high-speed and efficient UWOC links under all channel and turbulence conditions.

\subsection{Progress in laser based white light communications}

Investigations in UWOC can leverage on progress in terrestrial based optical communications, such as visible light communication (VLC), particularly in utilizing compact, small foot-print blue and green laser diodes for simultaneous illumination and high-speed (multiple Gbps) communication. A review is warranted since semiconductor lasers exhibit much higher modulation bandwidth than LEDs, and the utilization of indium gallium nitride ( $\mathrm{InGaN})$-based laser diode for VLC has recently ushered in significant progress.

A directly modulated $422 \mathrm{~nm}$ GaN-based TO-can laser diode showed a modulation bandwidth of $1.4 \mathrm{GHz}$, and $2.5 \mathrm{Gbps}$ VLC link. ${ }^{48)}$ Later, C. Lee et al. used a $450 \mathrm{~nm}$ laser diode with $2.6 \mathrm{GHz}$ 3- $\mathrm{dB}$ bandwidth for high speed VLC and a data rate of 4 Gbps was achieved using OOK modulation scheme. ${ }^{49)}$ Using a 64-quadrature amplitude modulation (QAM) and 32-subcarrier OFDM modulation technique, Y. Chi et al. reported a VLC link with a data rate of 9 Gbps. ${ }^{12)}$ In addition to violet-blue laser diode, $515 \mathrm{~nm}$ green laser diode and $640 \mathrm{~nm}$ red laser diode were also reported, and a data rate of 4 Gbps and 4.4 Gbps were achieved using 16 QAM-OFDM modulation scheme. ${ }^{50)}$

Further investigations show that both GaN-based edge emitting laser diodes (EELDs) and vertical-cavity surface-emitting lasers (VCSELs) exhibit a large modulation bandwidth beyond GHz. ${ }^{51}$, 52) Though the micro-pixel LEDs ( $\mu$ LEDs) have shown enhanced modulation characteristics compared to the conventional LEDs, their output powers are relatively low, making it less attractive for high brightness applications. ${ }^{13}{ }^{53)}$ Therefore, the InGaN-based laser diode became a competitive light emitter for both indoor and outdoor VLC systems.

Similar to the white LEDs illumination, lasers can be used to generate white light by blue coherent photons excitation of yellow-phosphor, which serve as a color converter. Therefore, the laser white light bulb offers both solid state lighting and VLC dual-functionalities. White light emission with a color rendering index (CRI) of $\sim 57$ and a correlated color temperature (CCT) of $\sim 4000 \mathrm{~K}$ has been measured using a $450 \mathrm{~nm}$ laser diode and YAG:Ce yellow-phosphor. ${ }^{54,55)}$ 
The CRI and CCT can be further improved by using violet-blue laser diode with a mixture of two or more types of phosphors. For instance, by using violet coherent photons excitation of a mixture of red-, green-, and blue-emitting (RGB) phosphors, white light with a CRI of $>90$ and a CCT of $\sim 2700 \mathrm{~K}$ has been reported. ${ }^{54)} \mathrm{A} \mathrm{CRI} \mathrm{of} \sim 89$ and $\mathrm{CCT}$ of $\sim 3200 \mathrm{~K}$ have been achieved when using a blue LD exciting a combination of novel green-emitting $\mathrm{CsPbBr}_{3}$ perovskite nanocrystals (NCs) and conventional red phosphor. ${ }^{56)}$ Apart from the white light characteristics, such as the CRI and CCT, the stability of phosphors is an important research topic owing to the fact that a significantly higher excitation power density is expected in LD based white lighting. ${ }^{57)}$ For high power laser based SSL lamp, the utilization of YAG:Ce single crystal phosphor plate has been investigated to reach a peak luminous flux of $1100 \mathrm{~lm} .{ }^{58)}$ Ceramic YAG:Ce yellow phosphor plates have also been developed for efficient white light generation under high power blue radiant flux density of $19.1 \mathrm{~W} / \mathrm{mm}^{2} .{ }^{59)}$ With the development of crystal and ceramic phosphors, laser based phosphorescent light bulbs offer new opportunities for future high brightness lighting.

The utilization of white light VLC, or "Li-Fi", has attracted increasing research interest owing to the growing demand for high-speed data communication links. ${ }^{60,61)}$ By direct modulation of a blue laser diode using a non-return-to-zero on-off keying (NRZ-OOK) modulation scheme, while exciting a YAG-based phosphor, 2 Gbps data transmission was achieved while white light was generated. ${ }^{55)} \mathrm{A} 3-\mathrm{dB}$ modulation bandwidth of $1.1 \mathrm{GHz}$ was measured without being limited by the lower $3.8 \mathrm{MHz}$ phosphor response. Simultaneous data communication and white light generation through violet coherent photons pumped RGB phosphors was also demonstrated recently. ${ }^{62)}$ The study of communication link performance based on off-the-shelf visible-light lasers shed light on a potential approach for optical wireless access with data rates towards 100 Gbps. $^{60)}$

\section{System}

\subsection{Light based underwater wireless communication link}

A typical UWOC system consists of three parts, the transmitter unit, the water channel and the receiver module. The schematic in Fig. 2 shows the components of such a system. The incoming information signal directly (or through a separate external optical modulator) modulates an optical light source which is usually an indium gallium nitride ( $\mathrm{InGaN}$ ) based semiconductor laser or LED. The optical light that generates the carrier wave has a wavelength and an output power of around 
$405-560 \mathrm{~nm}$ and $10 \mathrm{~mW}-1 \mathrm{~W}$, respectively. The optical beam is shaped by the projection optics and transmitted through the underwater channel. In the water channel, the signal is distorted due to several factors like optical turbulence (air bubbles, salinity gradient, and temperature gradient), scattering, absorption and background noise. In the receiver side, the transmitted optical beam is collected by the receiver lens and converted into electrical signal by a photodetector. Avalanche photodiode (APD) is the most common detector utilized in UWOC links due to its high level sensitivity.

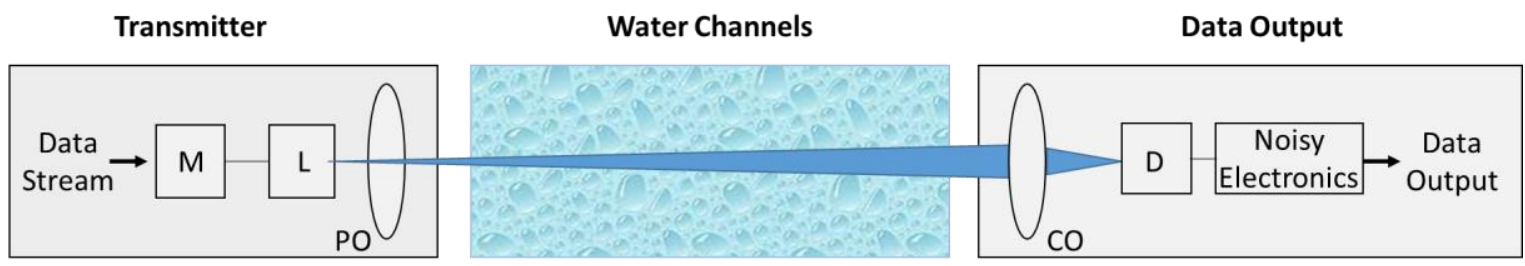

Fig. 2. (Color online) Schematic of a typical UWOC link. The transmitter is composed of a modulator (M), laser (L), and projection optics (PO) systems. The receiver is made of collection optics (CO), detector (D) and noisy electronics.

To achieve a large measurement dynamic range, reflective mirrors have been used on both sides of the water channel to bounce back and forth the light beam multiple times. Optical interference filters are used to suppress the ambient optical noise. Figure 3 presents an OOK UWOC system. As shown in the figure, the dynamic range of the link is extended up to $7 \mathrm{~m} .{ }^{30)}$

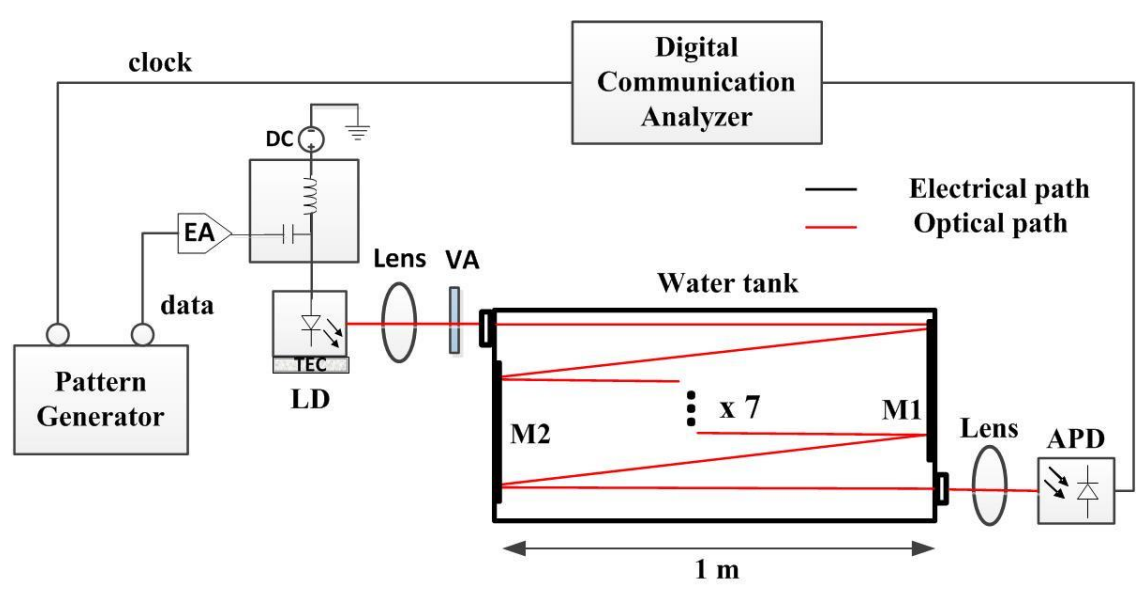

Fig. 3. (Color online) Experimental setup for underwater transmission measurements: electrical amplifier (EA), laser diode (LD), variable attenuator (VA), mirror (M1, M2), and avalanche photodetector (APD). (Reprint from ${ }^{30}$. Copyright 2015 Optical Society of America). 


\subsection{The underwater wireless optical channel}

The propagation of optical signals in underwater environment is complicated by the dynamics nature of optical clarity of water which changes from one location to another, from the surface to the bottom and from one day to the next. ${ }^{63)}$ The light beam in underwater experiences attenuation, temporal and spatial beam spreading, deflection from its geometrical path, and amplitude and phase distortions. Optical attenuation is a combination of absorption and scattering. The attenuation coefficient varies greatly depending on the concentration of suspended organic and inorganic sediments in the water column. Absorption is the process in which photons are converted into other forms of energy and thus are completely annihilated. Light absorption of pure water was exhaustively measured from $300 \mathrm{~nm}$ to $700 \mathrm{~nm}$ with high accuracy, ${ }^{64,65)}$ exhibiting a minimum between $400 \mathrm{~nm}-500 \mathrm{~nm}$. Figure 4(a) shows the absorption coefficient of light in seawater. ${ }^{9)}$ Note that as the amount of phytoplankton species and dissolved organic matters increase, the window of minimum absorption tends to shift from blue to green wavelengths. The transmittance of 405 , 550,650 , and $800 \mathrm{~nm}$ lights as a function of transmission distance obtained by Beer's law ${ }^{9,66)}$ is presented in Fig. 4(b).
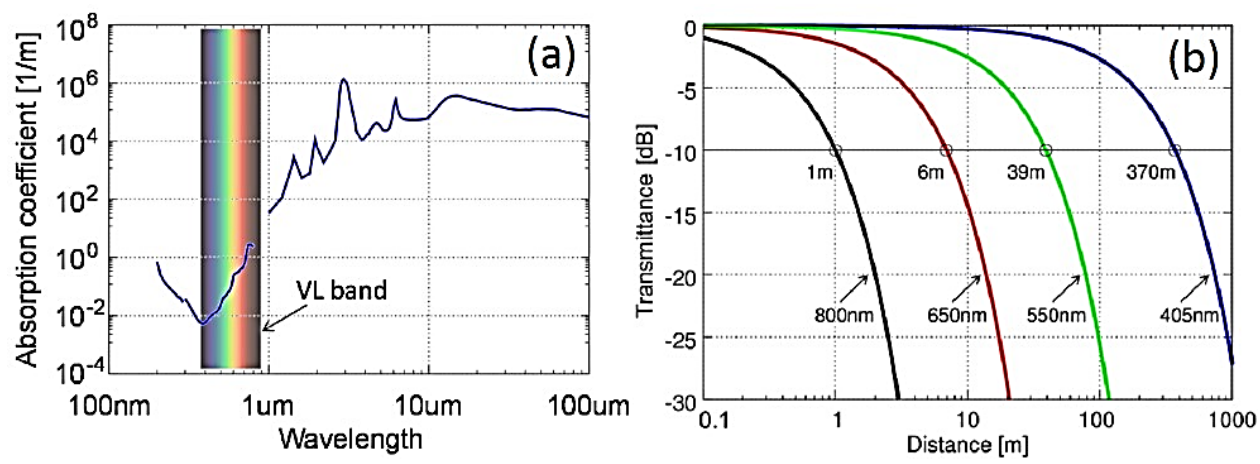

Fig. 4. (Color online) (a) Absorption coefficient of light in water. (b) Transmittance versus transmission distance for 405, 550, 650, and $800 \mathrm{~nm}$ lights. (Reprint from Ref 9. Copyright 2015 Optical Society of America).

Scattering is another optical phenomenon that impacts the performance of underwater communication systems. It is the process wherein the photon changes its direction as a result of its interaction with substances existing in the water environment. ${ }^{67)}$ As a result, the received optical power decreases which in turn reduces the signal-to-noise ratio (SNR) of the communication system. Underwater scattering is broadly categorized into three regimes, ${ }^{68)}$ namely molecular scattering $(<<\lambda)$, scattering by large particles $(>\lambda)$ and turbulent scattering $(\gg>\lambda)$. Molecular scattering or scattering by pure water arises from the density fluctuations and its effect on overall 
attenuation is negligible. Scattering by organic and inorganic large particles is the most common scattering in seawater and it is assumed to be homogeneous in nature.

Volume scattering function (VSF) which is the normalized angular distribution of scattered light is used to study the characteristics of light scattering in seawater. Series of studies on underwater scattering were carried out by Petzold, ${ }^{69}$ ) which showed that the VSF follows the small angle approximation and highly peaked in the forward direction. Underwater channels are often simulated using laboratory water tanks because of volatile platforms in the underwater environment. The water clarity level is changed by adding Maalox® solution, an over-the-counter antacid medication whose basic ingredients are aluminum hydroxide and magnesium hydroxide. Scattering properties of Maalox are found to be strikingly similar to the real ocean particles with forward scattering peak at small angles (less than $\left.10^{\circ}\right){ }^{21,70,71)}$ Figure 5 illustrates Petzold's VSF measurements of four different types of sea waters along with that of Maalox antacid. Note the similarity of the general shape of Maalox scattering function compared to each VSF of real ocean water. They are all highly peaked at very small angles except pure water indicating the significance of scattering in underwater optical signal propagation.

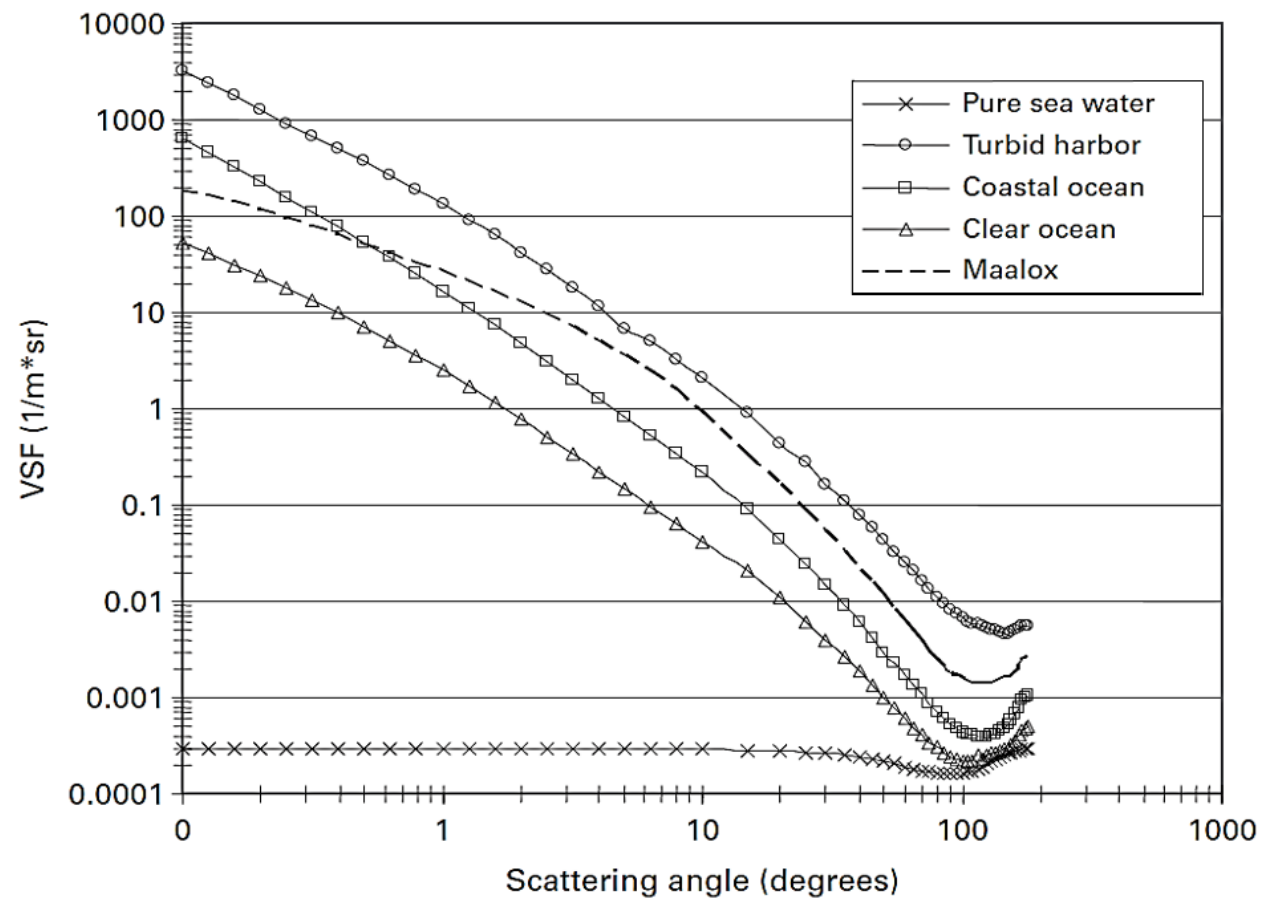

Fig. 5. (Color online) Experimental measurements of the scattering phase functions of various ocean water types and Maalox antacid by Petzold ${ }^{69)}$ and Duntley ${ }^{70)}$. Figure is taken from Ref. ${ }^{72}$. 


\subsection{Optical light sources}

The advancement of light sources has been vital for imaging/ranging, illumination and communications. Teledyne uses high power diode-pumped solid-state (DPSS) laser for bathymetry imaging up to $10 \mathrm{~m}$ undersea. Sonardyne uses high power LEDs and laser for wireless underwater video and vehicle control with a data rate of 2.5 to $12.5 \mathrm{Mbps}$ at ranges up to $150 \mathrm{~m}$. Optical communications based on lasers typically grown on sapphire substrates are commonly used due to the significant advantages of compactness and high bandwidth. Here, we review one aspect of the recent development in semiconductor light sources, which is based on wide bandgap nitride semiconductor grown on semipolar gallium nitride $(\mathrm{GaN})$ substrates.

3.3.1 Violet-blue superluminescent diodes (SLDs) Group-III nitride light-emitters, such as LEDs and LDs, have been demonstrated and studied for SSL and VLC applications. ${ }^{53,55,73)}$ However, the performance of LED-based SSL-VLC system is limited by "efficiency droop" and $<100 \mathrm{MHz} 3-\mathrm{dB}$ bandwidth. InGaN-based LDs were recently studied for "efficiency-droop-free", high-speed light-emitter. Notably, the semipolar-plane InGaN-based violet-blue emitting superluminescent diodes (SLDs) have been developed as a high-speed, high-brightness, and speckle-free light source, combining the advantages of LEDs and LDs. ${ }^{74)}$

The group-III nitride SLDs were fabricated using integrated passive absorber ${ }^{75)}$ and tilted facet $^{76)}$ configurations, emitting in the violet-blue region. The 446-nm emitting SLD, seamlessly integrating a $490-\mu \mathrm{m}$ absorber region and a $1000-\mu \mathrm{m}$ gain region, showed a broad spectral linewidth of $8.4 \mathrm{~nm}$ at an injection current of $500 \mathrm{~mA}\left(6.67 \mathrm{kA} / \mathrm{cm}^{2}\right) .{ }^{75)}$ The SLD generated $>200$ $\mathrm{mW}$ optical power in the amplified spontaneous emission (ASE) regime and the phosphorconverted white light exhibited a CRI of 64.4 and a CCT of $4094 \mathrm{~K}$. A 405-nm emitting SLD having a $590-\mu \mathrm{m}$ long tilted facet configuration showed a spectral linewidth of $9 \mathrm{~nm}$ at $400 \mathrm{~mA}$ $\left(16.9 \mathrm{kA} / \mathrm{cm}^{2}\right) .{ }^{76)}$ With a large 3-dB bandwidth of $\sim 800 \mathrm{MHz}$, the SLD showed a data rate of 1.3 Gbps using OOK modulation scheme. Such findings are applicable to underwater wireless optical communication and white light illumination.

3.3.2 Integrated photonics for visible light communications The white lighting and VLC functionalities have been demonstrated based on discrete components, such as group-III nitride violet-blue laser diodes, transverse-transmission modulators, and planar photodetectors. ${ }^{77}$, 
78) The monolithic integration of edge-emitting laser diodes together with modulators, amplifiers, and detectors forming a two-section device, has recently been investigated. Such on-chip integration offers many advantages, including small footprint, high speed, and low power consumption.

C. Shen et al. designed a blue-emitting integrated waveguide modulator-laser diode (IWM-LD) on a semipolar $(20 \overline{21})$-plane GaN substrate. $\left.{ }^{79}\right)$ The IWM-LD showed a high modulation efficiency of $2.68 \mathrm{~dB} / \mathrm{V}$. A large extinction ratio of $11.3 \mathrm{~dB}$ was measured in the violet-emitting IWM-LD. ${ }^{80)}$ Utilizing the integrated modulator instead of direct modulation of laser diode, Gbps data communication was demonstrated using OOK modulation scheme. In addition, the 404-nm integrated short-wavelength semiconductor optical amplifier (SOA) - laser diode has been fabricated, showing a large gain of $5.32 \mathrm{~dB}$ at $6 \mathrm{~V}$. ${ }^{81)}$ Such device can also be operated in the modulated amplifier scheme for high-speed VLC and potentially for UWOC. ${ }^{82)}$

Since the signal receiver is another essential component in VLC and UWOC systems, the highperformance waveguide photodetector (WPD) and its integration with LD at violet-blue color regime have been developed and characterized. ${ }^{83)}$ A significantly large 3-dB bandwidth of 230 $\mathrm{MHz}$ is measured in the WPD and can be further improved by reducing the form factor of the device. It is worth noting that both the WPD and LD are sharing the single active region, making it a promising structure to fabricate UWOC transceiver on a single chip.

These seamlessly integrated photonic IC in the visible wavelength holds potential for a number of applications. Smart lighting and display, free-space and underwater optical communications, optical switching, clocking, and interconnect $32,62,84,85)$ are expected to benefit from the development.

\subsection{Detectors}

One of the key components of UWOC is the light detection device or receiver. Designing a receiver to operate in the ocean environment is not like designing an ordinary communication receiver. The UWOC receiver system has to meet some basic requirements in order to overcome the effects of noise and attenuation. One of the most important parameters of the receiver is the FOV. To reduce the effects of incident solar background noise, the FOV is limited to small angles, around $10^{\circ}-30^{\circ}$. A device with a faster response time with flexible frequency response to adapt to the variability of the underwater environmental conditions (turbulences, Doppler effect, etc.) is highly desirable. In 
addition, the design of the receiver uses transimpedance amplifiers and other amplification techniques to increase internal gain up to more than 100 .

There are different types of receiver technologies. Vacuum tube based photo-multiplier tubes (PMTs) are characterized by high gain, low noise, and large active areas. However, PMT sensors are larger, more expensive, power hungry and their high frequency response does not support Gbps data transmission required in advanced underwater applications. PIN photodiodes are sometimes used but the most common are the avalanche photodiodes (APD). ${ }^{21,32)}$ Current APDs are characterized by a frequency response of up to $1.2 \mathrm{GHz}$ and a large internal gain $(\leq 100) .{ }^{30)}$ To suppress the large amount of environmental optical noise, significant progress has been made on more advanced light detection devices such as solar-blind photodetectors and single photon detectors. In the following, a snapshot of the development of photodetector technologies is presented, with the objective of inspiring innovations in underwater photodetection.

3.4.1 Solar-blind photodetectors The liquid water absorption spectra dips in the visible and ultraviolet (UV) wavelength regions, which opens up a transmission window for long distance and high data rate communication links. ${ }^{65,86)}$ Specifically, the solar-blind spectrum region from 200 $\mathrm{nm}$ to $280 \mathrm{~nm}$ is of great interests owing to the extremely low background noise and the effective atmospheric scattering for non-line-of-sight (NLOS) communication. As compared to the development of emitters, i.e. LEDs, LDs and SLDs, the investigation of receivers used for solarblind UWOC communication is still lagging behind. ${ }^{87-94)}$ Silicon based PDs and APDs have been used in the prior UWOC systems, but the bandgap limitation severely reduce the feasibility of them in solar-blind region. Currently, InGaN based PD is being developed in the near UVA spectrum region $(405 \mathrm{~nm}) .{ }^{82)}$ High efficiency and high speed photodetector in solar blind region will become crucial as the detection wavelength gets deeper in UV spectrum.

The detection of UV light can be achieved by using semiconductor photodetectors (PDs), thermal detectors, charge-coupled devices (CCD) or PMT. ${ }^{92)}$ Semiconductor, especially direct bandgap materials with energy bandgap larger than $4.4 \mathrm{eV}$ are the optimal material options of solar-blind photodetectors owing to several advantages of efficient light absorption and robustness suitable for various harsh environments, such as corrosive seawater. Figure 6 summarizes the bandgap and bond length of the wide bandgap materials ranging from III-V compounds of AlN, $\mathrm{GaN}$ and $\mathrm{BN}$, to II-VI compounds of $\mathrm{MgS}, \mathrm{ZnS}$ and $\mathrm{MgSe}$, to $\mathrm{Ga}_{2} \mathrm{O}_{3}$ and diamond. ${ }^{95}$ ) 


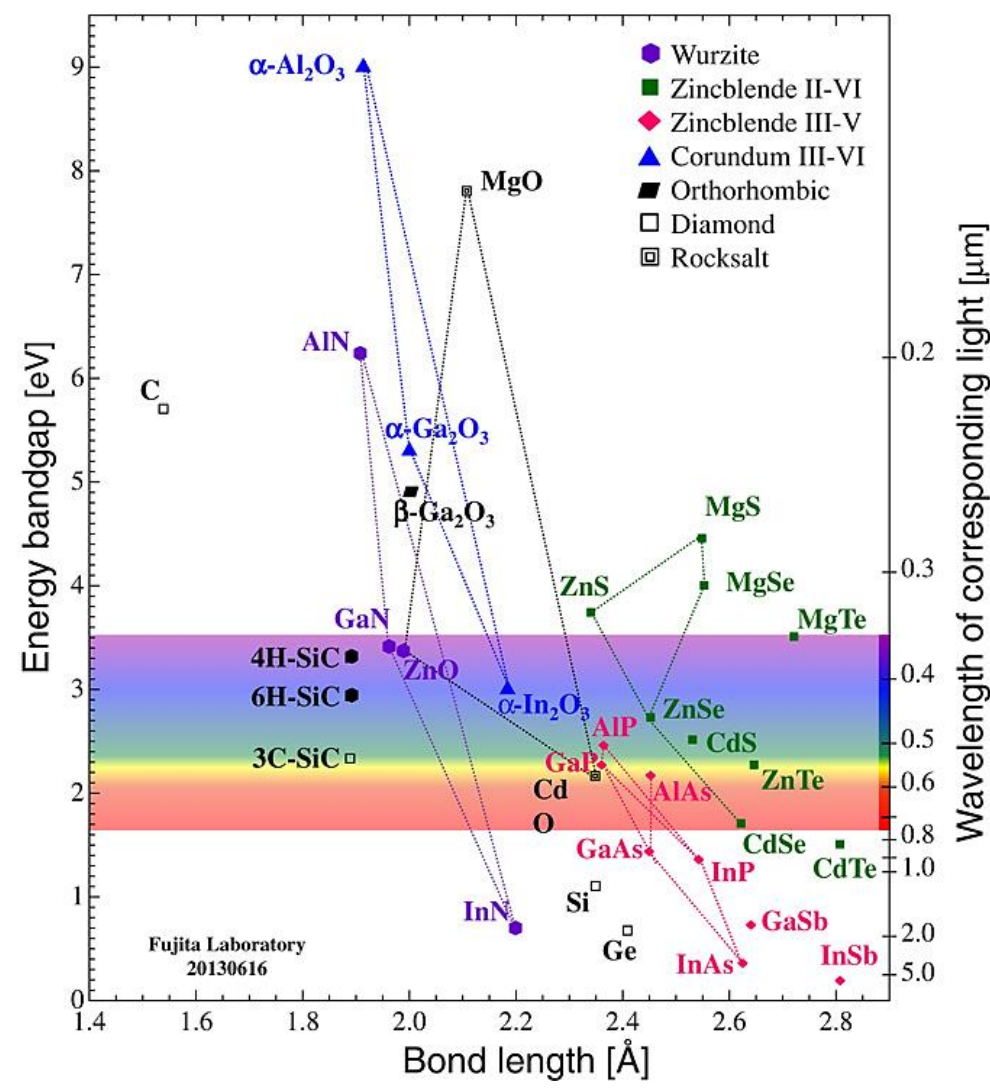

Fig. 6. (Color online) Band diagram of various wide bandgap materials. (Reprint from ${ }^{95}$. Copyright 2015 The Japan Society of Applied Physics).

Table II. Summary of solar-blind photodetector based on wide bandgap materials

\begin{tabular}{|c|c|c|c|c|c|c|}
\hline \multirow[t]{2}{*}{$\begin{array}{l}\text { Authors } \\
\text { (Year) }\end{array}$} & \multirow[t]{2}{*}{ PD type } & \multirow[t]{2}{*}{$\begin{array}{c}\lambda_{\text {range or }} \\
\lambda_{\text {peak }}\end{array}$} & \multirow[t]{2}{*}{$R(\mathrm{~A} / \mathrm{W})$} & \multicolumn{2}{|c|}{$\begin{array}{l}\text { Transient } \\
\text { response }\end{array}$} & \multirow[t]{2}{*}{ Bandwidth } \\
\hline & & & & $t_{\text {rise }}$ & $t_{\text {fall }}$ & \\
\hline $\begin{array}{l}\text { J. C. Carrano }{ }^{96)} \\
\text { (UT-Austin) } \\
\text { (1998) }\end{array}$ & GaN MSM & $267 \mathrm{~nm}$ & - & $28 \mathrm{ps}$ & - & $3.5 \mathrm{GHz}$ \\
\hline $\begin{array}{l}\text { J. C. Carrano } \\
\text { (UT-Austin) }^{96} \\
\text { (1998) }\end{array}$ & GaN PIN & $267 \mathrm{~nm}$ & - & $43 \mathrm{ps}$ & - & $1.4 \mathrm{GHz}$ \\
\hline $\begin{array}{l}\text { A. Osinsky }{ }^{97)} \\
\text { (APA Opt Inc) } \\
\text { (1998) }\end{array}$ & AlGaN MSM & $240-290 \mathrm{~nm}$ & 0.07 & - & $1.6 \mu \mathrm{s}$ & - \\
\hline $\begin{array}{l}\text { C. Pernot }{ }^{98)} \\
\text { (Univ. Montpellier II) } \\
\text { (2000) }\end{array}$ & $\begin{array}{c}\mathrm{GaN} / \mathrm{AlGaN} \\
\text { PIN }\end{array}$ & $270 \mathrm{~nm}$ & 0.012 & - & $14 \mu \mathrm{s}$ & - \\
\hline T. Tut ${ }^{99)}$ & $\mathrm{AlGaN}$ & $256 \mathrm{~nm}$ & 0.147 & $26 \mathrm{ps}$ & - & $4.1 \mathrm{GHz}$ \\
\hline
\end{tabular}




(Bilkent Univ.) Schottky diode
(2005)

T. Tut ${ }^{100)}$

(Bilkent Univ.) $\quad$ AlGaN PIN $\quad 266 \mathrm{~nm} \quad 0.093$

(2008)

S. Rathkanthiwar ${ }^{101)}$

(Indian Inst. Sci.)

(2017)

AlGaN MSM $\quad 245-190 \mathrm{~nm} \quad 5$

A. Soltani ${ }^{102)}$

(Raytheon BBN

Tech.)

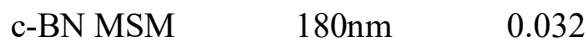

(2008)

H. Srour ${ }^{103)}$

$\begin{array}{llcllll}\text { (Univ. Lorraine } & \& & \begin{array}{c}\text { BGaN/GaN SL } \\ \text { Supelec) }\end{array} & 375 \mathrm{~nm} & 0.03 & 15 \mathrm{~ns} & 44 \mathrm{~ns}\end{array}$

(2011)

T. C. Doan ${ }^{104)}$

(Texas Tech Univ.) h-BN MSM $217 \mathrm{~nm}$

(2016)

C. Soci ${ }^{105)}$

(UCSD)

(2007)

ZnO NW MSM $\quad 250-390 \mathrm{~nm}$

$-\quad-\quad 20 \mathrm{~ns}$

M. Nakano ${ }^{106)}$

(Tohoku Univ.)

(2008)

ZnO Schottky 240nm-

diode $\quad 380 \mathrm{~nm}$

0.3

J. Du ${ }^{107)}$

(China Univ. of $\beta-\mathrm{Ga}_{2} \mathrm{O}_{3} \mathrm{NW}$

Geosciences) MSM

$231 \mathrm{~nm}$

$377 \quad 0.8 \mathrm{~ns} \quad 12 \mathrm{~ns}$

(2016)

A. Singh Pratiyush ${ }^{108)}$

(Indian Inst. Sci.)

(2017)

B. Zhao ${ }^{109)}$

(Fudan Univ.)

(2017)

$\beta-\mathrm{Ga}_{2} \mathrm{O}_{3} \mathrm{MSM}$

$236 \mathrm{~nm}$

1.8

$3.33 \mathrm{~s} \quad 0.4 \mathrm{~s}$

A. BenMoussa ${ }^{88)}$

(STCE)

$\mathrm{ZnO}-\mathrm{Ga}_{2} \mathrm{O}_{3}$

Core-shell wire

$251 \mathrm{~nm}$

$9.7 \mathrm{e}-3$

$100 \quad 400$

(2009)

Diamond MSM $\quad 210 \mathrm{~nm} \quad 0.048$

L. Wang ${ }^{110)}$

(CAS)

(2009)

MgZnO MSM

$268 \mathrm{~nm}$

0.016

$10 \mathrm{~ns}$

150

Y. N. Hou ${ }^{111)}$

(CAS)

(2011)

$\mathrm{MgZnO} / \mathrm{Si} \mathrm{PN}$

$250-300 \mathrm{~nm}$

1

$\sim \mathrm{s} \quad 4 \mathrm{~s}$

Y. D. Zhu ${ }^{112)}$

$\mathrm{MgZnO} / \mathrm{ZnO} \quad 300 \mathrm{~nm}$

0.45

$4 \mathrm{~s} \quad 4 \mathrm{~s}$ 
(Wuhan Univ.)

(2012)

Y. Guo ${ }^{113)}$

(The Univ. of Tokyo)

(2015)
MSM

Perovskite MSM
$200-400 \mathrm{~nm}$
$0.2 \mu \mathrm{s} \quad 0.7 \mu \mathrm{s}$

The two main characteristics of solar-blind PDs for communication applications are detection sensitivity and speed. The performance of I-V curves, responsivity $(R)$ spectrum, rejection ratio and efficiency are important parameters for photodetection. The signal rise time, decay/fall time and bandwidth are used for determining modulation speed in data transmission. Table II summarizes the performance of semiconductor based solar-blind PDs. ${ }^{88,96-113)}$ The table is ordered by the use of different groups of materials. As indicated in the table, III-nitride based PDs are among the first and ideal choices for high efficiency and high-speed devices. The direct bandgap AlGaN material is tunable from its binary alloy from $3.4 \mathrm{eV}(\mathrm{GaN})$ to $6.2 \mathrm{eV}(\mathrm{AlN})$ at room temperature enables the wide spectrum coverage from blue to UVC. ${ }^{97-101,114,115)}$ The past 20 years have witnessed the improvement in $\mathrm{AlGaN}$ based PDs with different device configurations of metal-semiconductor-metal (MSM), PN heterostructure, PIN and Schottky diodes. ${ }^{90,94)}$ The bandwidth can reach GHz range. Besides, boron nitride (BN) based PDs begin to attract substantial attentions for solar-blind detection ${ }^{102-104)}$ due to a wide bandgap of $5.2 \mathrm{eV}$ (hexagonal BN) or 6.4 $\mathrm{eV}$ (cubic BN). ${ }^{116)}$

In addition, groups of novel materials including $\mathrm{ZnO},{ }^{105,106)} \mathrm{Ga}_{2} \mathrm{O}_{3},{ }^{107-109)} \mathrm{MgZnO}^{110-112)}$ and 2D Perovskite and nanostructures in the form of superlattice (SL), nanowires (NW), core-shell structures ${ }^{109)}$ have emerged thanks to the advances in material growth and fabrication techniques. The transient response, or stability of these novel solar-blind PDs still requires further investigation, and implementation of these devices in communication are still lacking. Nevertheless, wide bandgap semiconductor based solar-blind PDs are exhibiting great potential and may hold potential for UWOC applications.

3.4.2 Single photon detection Along with the considerable interest in the development of UWOC systems, this section reviews the conventional single photon detection technique for highly efficient long range detection communications. As explained, advances in terrestrial or space optical communication can be adopted for technology innovations custom-designed for underwater communications. As such, the usage of single photon transmission in the optical 
communication link could potentially provide high detection, high accuracy and low noise measurements. ${ }^{117)}$ The accelerated development of single-photon emitters and detectors technologies have contributed to various applications, e.g. quantum optics, quantum communication, optical quantum computing and space-to-ground optical communication. In the field of UWOC, Hiskett and Lamb are among the earliest groups to investigate the feasibility of photon-counting system in the underwater transmission of encoded optical pulse patterns by using SPAD through a $1 \mathrm{~m}$ long of water tank (see Fig. 7(a)). ${ }^{118)}$ Apart from that, an energy-saving VLC link with SPAD receiver in underwater environment has also been employed in continuous downhole monitoring of gas well as shown by $\mathrm{Li}$ et al. ${ }^{119)}$ The simulation results demonstrated that by using SPAD arrays, the emitter required only $8 \mathrm{dBm}$ power for VLC link in a $4000 \mathrm{~m}$ long pipe, thus ensuring a sufficiently long time of self-sustaining operation for an emitter in deep sea environment. In addition, the BER performance of SPAD at different transmission speed is also shown in Fig. 7(b). More recently, Shafique et al. also presented the performance of long transmission and error-free UWOC system by jointly using automatic repeat request (ARQ) and SPAD to mitigate turbulence in underwater environment. ${ }^{120)}$ A $500 \mathrm{~m}$ long UWOC system with pure seawater has also been demonstrated by Wang et al., where they showed that the SPAD receiver is able to extend the transmission distance up to $112 \mathrm{~m}$ at the target BER of $10^{-6}$, as compared to that of avalanche photodiode (APD) which can only achieve $73 \mathrm{~m}$ at the same BER, shown in Fig. 7(c). ${ }^{121)}$ 
(a)

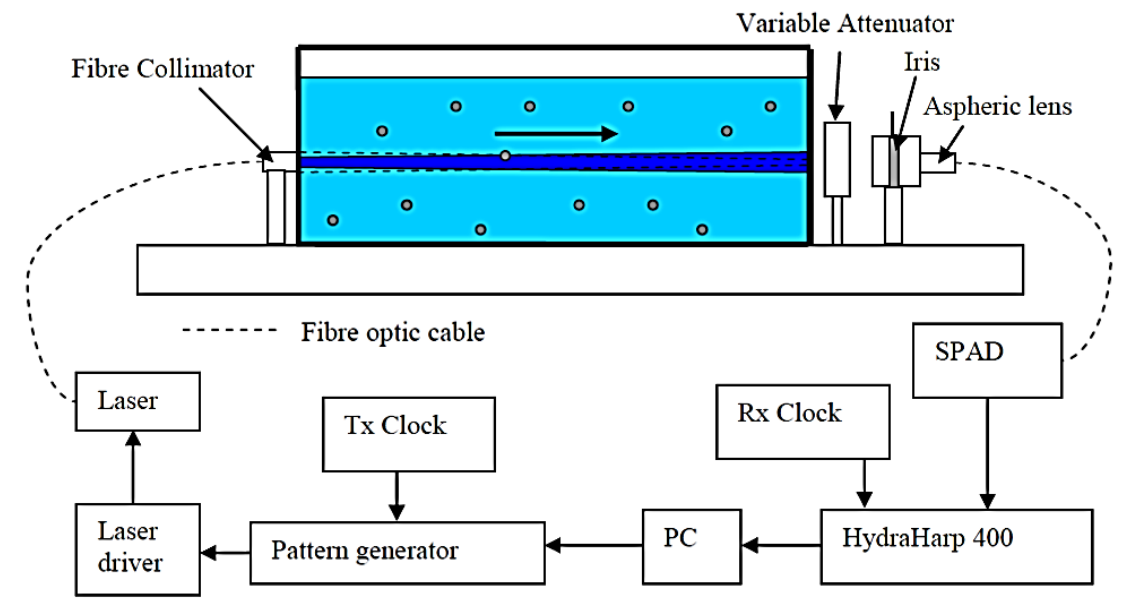

(b)

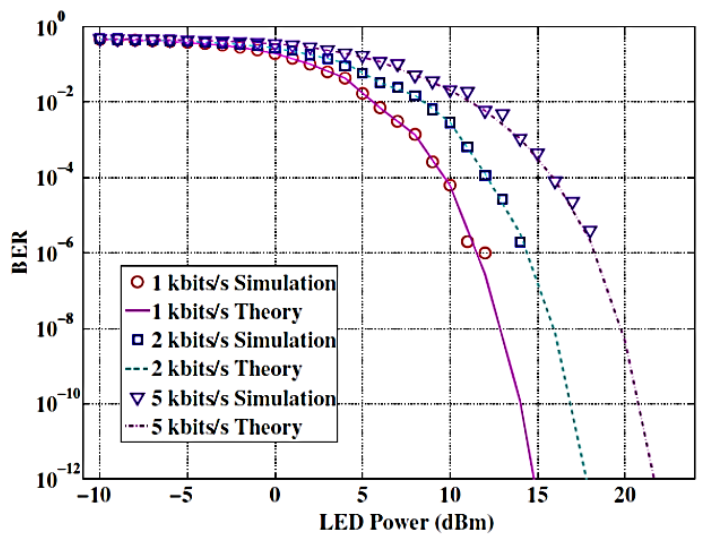

(c)

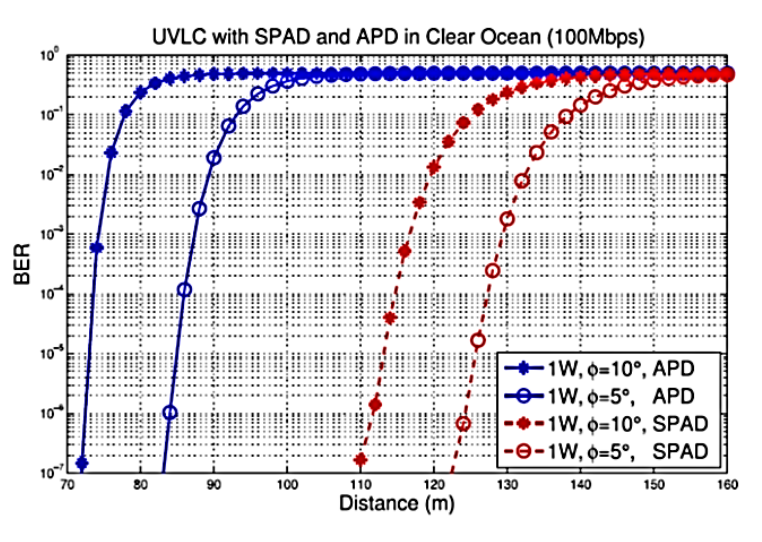

Fig. 7. (Color online) (a) Schematic illustration of the experimental setup of photon-counting communication system through a $1 \mathrm{~m}$ long water tank by using SPAD (Reprint from ${ }^{118)}$ ). (b) The BER performance of SPAD in a $4 \mathrm{~km}$ long metal pipe at different transmission speed for practical application in downhole monitoring (Reprint from ${ }^{119)}$. Copyright 2014 IEEE Global Communications Conference). (c) The simulated comparison of BER performance between APD and SPAD for UWOC communication system (Reprint from ${ }^{121)}$. Copyright 2016 IEEE Photonics Journal).

Single-photon detector could provide several advantages, e.g. high receiver sensitivity and incoherently combine signal from multiple spatial mode. ${ }^{122)}$ Nevertheless, the performance of optical communication link depends on the timing jitter, recovery time and detection efficiency of the single-photon detectors. As compared to conventional PMT and silicon-based SPAD used in most of the current UWOC demonstrations, some of the recently emerging single-photon detector technologies include: (1) ultrathin-film superconducting single-photon detectors (SSPD) and (2) superconducting nanowire single-photon detectors (SNSPD). These newly developed singlephoton detector technologies are largely motivated by the bulky, fragile and expensive cost 
associated with PMT. ${ }^{123)}$ In particular, although PMT is able to offer larger active areas, it has very low efficiency of $<5 \%$ in the visible wavelength regime. ${ }^{117)}$ As mentioned, in recent years, some of the emerging single-photon detector technologies promise higher detection efficiency, lower dark current count, higher count rate and photon-number resolving capability, as compared to conventional single-photon detector. In addition, both PMT and SPAD have maximum counting rates of approximately $100 \mathrm{MHz}$ and below, thus it might not be a suitable candidate for future GHz optical communication link. ${ }^{123)}$ Here, we have selected a number of promising single-photon detector, other than PMT and SPAD receiver, which is worth exploring for employment in secure UWOC system in the future. However, despite a better device performance, such detectors require very low operating temperature $(<4 \mathrm{~K})$ with sophisticated cooling technology.

For SSPDs, Verevkin et al. is one of the earliest group to demonstrate niobium nitride $(\mathrm{NbN})$ ultrathin-film SSPD for GHz-rate free space optical communication. ${ }^{124)}$ The demonstrated 3.5-nmthick NbN SSPDs exhibited quantum efficiency (QE) of up to the theoretical maximum of $\sim 100 \%$ at visible wavelengths region and $\sim 35 \%$ at infrared region. Moreover, the low intrinsic jitter $(<35$ ps) and low dark current of the detectors showed the prospective of NbN SSPDs for reaching up to ultrafast $10-\mathrm{GHz}$ counting rates.

On the other hand, high-speed and high-efficiency SNSPD has also been widely demonstrated with fast recover time $(<10 \mathrm{~ns})$, low jitter $(<100 \mathrm{ps})$ and low dark count rates. It has been widely reported that thin and narrow superconducting wires in SNSPD typically yield low recovery time of a few nanoseconds, thus indicating the scalability of SNSPD for future imaging and GHz-countrate applications. ${ }^{122,125)}$ For example, Verma et al. reported on high system detection efficiency of $\sim 87 \%$ at $1542 \mathrm{~nm}$ by using MoSi SNSPD. ${ }^{126)}$ At operating temperature of $0.7 \mathrm{~K}$, the timing jitter was about $76 \mathrm{ps}$ and the maximum count rate was $10 \mathrm{MHz}$. And more recently, Slichter et al. demonstrated the application of MoSi SNSPD at detection wavelength down to $315 \mathrm{~nm} .{ }^{127)}$ At 3.2 $\mathrm{K}$, the system detection efficiency was about $76 \%$ with background count rate (BCR) of below 1 count per second (cps).

In parallel with the ongoing effort to improve single photon detection technologies and even to a wider range of applications, small size and large arrays of SNSPD has also been demonstrated. For instance, Rosenberg et al. reported on NbN-based SNSPD arrays with approximately $76 \%$ fiber-coupled system detection efficiency at $1550 \mathrm{~nm} .{ }^{128)}$ The NbN-based SNSPD arrays has a low dark count rates and timing jitter of between 60 to 80 ps. Similarly, Casaburi et al. reported on 
small single pixel NbTiN SNSPD arrays $\left(30\right.$ x $\left.30 \mu \mathrm{m}^{2}\right)$ for future infrared photon counting applications. ${ }^{129)}$ The array demonstrated low timing jitter of $\sim 71$ ps and dark count rate of $\sim 250$ Hz. A table of comparison for several different types of single-photon detectors is summarized in Table III. A detailed theory and technical reviews covering the topic can be found in Dauler et al. ${ }^{125)}$, Chunnilall et al. ${ }^{130)}$, Shigeki et al. ${ }^{131)}$, Hadfield et al. ${ }^{117)}$ and Eisaman et al. ${ }^{123)}$.

Table III. Performance comparison of different scheme of single-photon detectors

\begin{tabular}{|c|c|c|c|c|c|c|}
\hline Authors & $\begin{array}{l}\text { Type of } \\
\text { Detector }\end{array}$ & $\begin{array}{l}\text { Operation } \\
\text { Temperature } \\
\text { (K) }\end{array}$ & $\begin{array}{l}\text { Spectral } \\
\text { Range }\end{array}$ & $\begin{array}{l}\text { Maximum } \\
\text { Count Rate } \\
\text { (D) }\end{array}$ & $\begin{array}{l}\text { Detection Efficiency } \\
\text { ( } \eta \text { ) Wavelength }\end{array}$ & $\begin{array}{l}\text { Timing } \\
\text { Jitter }(\Delta t)\end{array}$ \\
\hline $\begin{array}{l}\text { Hamamatsu } \\
\text { (Commercial) } \\
\text { (2009) }\end{array}$ & PMT & 300 & $\begin{array}{l}\text { Visible to } \\
\text { NIR }\end{array}$ & $10 \mathrm{MHz}$ & 40\%@500 nm & $300 \mathrm{ps}$ \\
\hline $\begin{array}{l}\text { Thomas et al. } \\
\text { (Cambridge) } \\
\text { (2010) }\end{array}$ & Si SPAD & 250 & Visible & $16 \mathrm{MHz}$ & 74\%@600 nm & - \\
\hline $\begin{array}{l}\text { Ghioni et al. }{ }^{133)} \\
\text { (Politecnico di } \\
\text { Milano) } \\
\text { (2009) }\end{array}$ & Si SPAD & 78 & Visible & $10 \mathrm{MHz}$ & $\begin{array}{l}\text { 42\%@780 nm } \\
\sim 34 \% @ 850 \mathrm{~nm}\end{array}$ & 35 ps \\
\hline $\begin{array}{l}\text { Blakesley et al. }{ }^{134)} \\
\text { (Toshiba Research) } \\
\text { (2005) }\end{array}$ & $\begin{array}{l}\text { QD } \\
\text { Resonant } \\
\text { Tunnel } \\
\text { Diode }\end{array}$ & 4 & Visible & $250 \mathrm{kHZ}$ & 12\%@550 nm & $150 \mathrm{~ns}$ \\
\hline $\begin{array}{l}\text { Verevkin et al. }{ }^{\text {124) }} \\
\text { (Rochester) } \\
\text { (2002) }\end{array}$ & NbN SSPD & 4.2 & $\begin{array}{l}\text { Visible to } \\
\text { IR }\end{array}$ & $10 \mathrm{GHz}$ & $\begin{array}{l}\sim 10 \% @ 405 \mathrm{~nm} \\
\sim 5 \% @ 1550 \mathrm{~nm}\end{array}$ & $35 \mathrm{ps}$ \\
\hline $\begin{array}{l}\text { Verma et al. }{ }^{126)} \\
\text { (NIST, Boulder) } \\
\text { (2015) }\end{array}$ & $\begin{array}{l}\text { MoSi } \\
\text { SNSPD }\end{array}$ & 0.7 & IR & $10 \mathrm{MHz}$ & 〜87\%@1542 nm & $76 \mathrm{ps}$ \\
\hline $\begin{array}{l}\left.\text { Slichter et al. }{ }^{127}\right) \\
\text { (NIST, Boulder) } \\
\text { (2017) }\end{array}$ & $\begin{array}{l}\text { MoSi } \\
\text { SNSPD }\end{array}$ & 3.2 & UV & $0.2 \mathrm{MHz}$ & 76\%@315 nm & $11 \mathrm{~ns}$ \\
\hline
\end{tabular}

In recent years, the rapid development of SSPD and SNSPDs have attained a high level of maturity in device performance, offering comparable and outperforming characteristics (e.g. high detection efficiency, low dark count and low timing jitter) as compared to older PMT and SPAD technology. This was also coupled with rapid advances in the electrical and optical integration with the detection system. Nevertheless, the need for advance and high complexity cooling technology in SSPD and SNSPD constitute a major drawback. ${ }^{135)}$ Furthermore, SSPD and SNSPD are so far 
demonstrated for communications in the infrared wavelength region, and hence much experimental work are needed in employing SSPD and SNSPD in ultraviolet-visible (UV-VIS) optical communication, particularly in underwater environment. Recently, Ji et al. demonstrated feasibility of quantum cryptography and quantum communication in free-space seawater as quantum channel using a $3.3 \mathrm{~m}$ long water tank. ${ }^{136)}$ The results demonstrated relatively high process fidelity of about $98 \%$ in both seawater and distilled water samples. Furthermore, no significant changes in polarization correlated quantum states and high fidelity of 0.9946 were observed for entangled photon source at $810 \mathrm{~nm}$, indicating the practicability of high-path-loss open seawater as quantum channel.

Some of the current work also includes design of broadband high-efficiency SNSPD ${ }^{135,137)}$ and large-scale SNSPD arrays ${ }^{128,129)}$. Recently, Tentrup et al. demonstrated high-dimensional encoding of single photons of up to 10 bits per photon, breaking the previous record of 7 bits. Such development can potentially improve speed and security in quantum communication, particularly for highly secured military-level communication between the submarines. ${ }^{138)}$ As pointed out by many other leading groups in this technology, the continuous improvement in the SNSPD technology promises single photon communication with high-bit-rate, longer distance, higher sensitivity, better security and lower background noise. ${ }^{117,123,125)}$ This field of technology could ultimately open up a potential path towards high efficiency $\mathrm{GHz}$ underwater optical communication links.

\subsection{UWOC link configurations}

UWOC link configurations are generally discussed based on the FOV between the optical transmitter and optical receiver (see Fig. 8), and classified as LOS, diffused LOS, and NLOS, with retroreflector LOS being a variant of LOS communication.

3.5.1 LOS and NLOS communications Currently, most of the UWOC links are based on LOS arrangement, in which the transmitter and the receiver are perfectly aligned. This configuration may offer data rate up to and beyond $10 \mathrm{Gbps}$ by using narrow-beam transmitters and photon-counting receivers designed to operate with error correction coding. ${ }^{139)}$ Although high data rate and long transmission distance can be achieved with this configuration, the performance will be deteriorated in the presence of turbulences, ${ }^{29,46)}$ scattering and absorption, as well as 
blockages between the transmitters and receivers undersea. In diffuse-LOS or NLOS communication, the FOV for both transmitter and receiver are not pointed to each other directly (see Fig. 8). Rather, the transmitted radiation will be redirected one time or multiple times before arriving at the detector through molecular scattering. Thus, diffuse-LOS or NLOS communications relaxes the strict requirements in position, acquisition and tracking (PAT).

According to Rayleigh scattering, shorter wavelength contributes to a stronger scattering effect, and thus is favorable for NLOS communication. Since the short wavelength blue radiation has the lowest water absorption, which can penetrate the blue ocean over $100 \mathrm{~m}$, NLOS can be effectively implemented using violet (405 nm) - blue (450 nm) lasers.

Prospects of utilizing even shorter wavelengths for enhancing scattering undersea remain unexplored. In the following, by turning to current progress in terrestrial UV NLOS communication, we attempt to shed light on research gap in UWOC which has not been adequately addressed experimentally. It is expected that experience gained in terrestrial communication can be applied to submarine scenarios with adequate consideration in the characteristics of water and its turbidity.

Terrestrial NLOS communications studies are mainly based on ultraviolet due to its noiseless background, especially for UVB (280-315 nm)/UVC (100-280 nm). This noiseless environment is caused by the absorption from ozone when the solar radiation passes through the earth atmosphere. ${ }^{140)}$ Consequently, a high SNR diffuse-LOS or NLOS communication link is feasible for the UV band. It is noted that attenuations and multiple paths, brought about by absorption and scattering, can be diminished by using extremely sensitive detectors, such as PMTs and intersymbol-interference mitigation modulation schemes, such as OFDM. ${ }^{141)}$ 


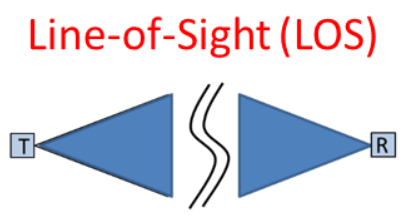

(a)

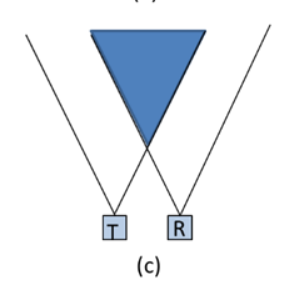

Diffuse-LOS

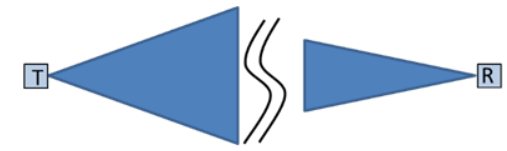

(b)

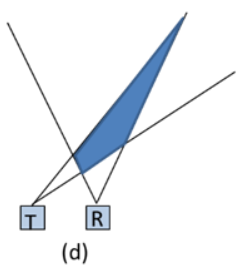

(d)

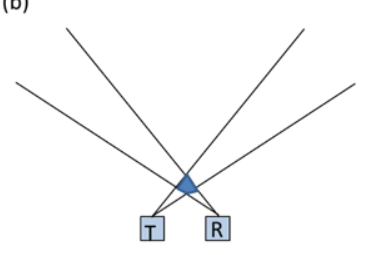

(e)

\section{Non-LOS (NLOS)}

Fig. 8. (Color online) (a) Line-of-sight (LOS) link. (b) Diffuse-LOS link. (c,d,e) Non-LOS link. ${ }^{141)}$

In the absence of compact and energy efficient UV devices, including UV transmitter and receiver, theoretical modeling was the focus of majority of the early work. Experimental studies on UV optical communications dated back to as early as $1964,{ }^{142}$ ) in which discussions on system components including sources, filters, and receivers were provided. In 1968, a study on the components selection and integration was made to develop the setup by utilizing a xenon flash lamp. ${ }^{143)}$ The earliest UV communication system was demonstrated by employing a flash lamp to transmit voice in 1976. ${ }^{144)}$ Later, in the 1990s, tactical battlefield application of UV NLOS communications was proposed, a data rate of $1.2 \mathrm{Mbps}$ over $1.63 \mathrm{~km}$ transmission distance was achieved based on a PMT covered with a solar blind filter and a collimated, continuously emitting lamp with a high-speed electro-optical switch. ${ }^{145)}$ Another demonstration of $10 \mathrm{kbps}$ data rate using a 253-nm Hg-Ar lamp was achieved over $0.5 \mathrm{~km} .{ }^{146)}$ Another UV digital communication system based on a 254-nm low-pressure mercury lamp and PMT covered with solar blind filter was established. With the modulation scheme of frequency shift keying (FSK), the bit rate achieved was $1.2 \mathrm{kbps}$ with a system BER of $\sim 10^{-4}$ when the transmitter aperture angle is 60 degrees. ${ }^{147)}$ However, with advances in UVB/UVC LEDs, higher data rates are realized due to their higher bandwidth compared to previous UV flash lamps which have lower modulation bandwidth. In 2012, an experimental NLOS test-bed utilizing a 265-nm UVC LED and diversity reception technology integrated with equal-gain-combining (EGC) scheme and modulated by OOK demonstrated a data rate of $2.4 \mathrm{kbps}$ over $100 \mathrm{~m} .{ }^{148)}$ Very recently, a diffuse-LOS communication link with high data-rate of 71 Mbps was implemented by using a $294 \mathrm{~nm}$ UVB LED and an 
APD. ${ }^{141)}$ In the experiment, OFDM modulation was adopted to mitigate intersymbol-interference (ISI) for improving link performance. Table IV provides a summary of data rates achieved in those studies.

Table IV. Performance of achieved data rates for NLOS/Diffuse-LOS communications

\begin{tabular}{|c|c|c|c|c|c|c|}
\hline Authors & $\begin{array}{l}\text { Modulation } \\
\text { Scheme }\end{array}$ & Light Source & $\begin{array}{c}\text { Photo- } \\
\text { detector }\end{array}$ & $\begin{array}{c}\text { Transmission } \\
\text { Power }\end{array}$ & $\begin{array}{l}\text { Channel } \\
\text { Length }\end{array}$ & $\begin{array}{l}\text { Data } \\
\text { Rate }\end{array}$ \\
\hline $\begin{array}{l}\text { M. Geller }{ }^{146)} \\
\text { (U.S. Dept. } \\
\text { of the Navy) } \\
\text { (1985) }\end{array}$ & PPM & $\begin{array}{c}253 \mathrm{~nm} \mathrm{Hg}-\mathrm{Ar} \\
\text { lamp }\end{array}$ & PMT & $5 \mathrm{~W}$ & $0.5 \mathrm{~km}$ & $10 \mathrm{kbps}$ \\
\hline $\begin{array}{l}\text { J. J. Puschell1 }{ }^{145)} \\
\text { (TITAN Syst.) } \\
\text { (1990) }\end{array}$ & PPM & $\begin{array}{c}265 \mathrm{~nm} \mathrm{Hg}-\mathrm{Xe} \\
\text { lamp }\end{array}$ & PMT & $25 \mathrm{~W}$ & $1.6 \mathrm{~km}$ & $1.2 \mathrm{Mbps}$ \\
\hline $\begin{array}{l}\text { D. Han }{ }^{148)} \\
\text { (SIOM, CAS) } \\
\text { (2012) }\end{array}$ & OOK/PPM & $265 \mathrm{~nm}$ LED & PMT & $43 \mathrm{~mW}$ & $100 \mathrm{~m}$ & $2.4 \mathrm{kbps}$ \\
\hline $\begin{array}{l}\text { B. S. Ooi }{ }^{141)} \\
\text { (KAUST) } \\
\text { (2017) }\end{array}$ & OFDM & 294 nm LED & APD & $190 \mu \mathrm{W}$ & $8 \mathrm{~cm}$ & $71 \mathrm{Mbps}$ \\
\hline
\end{tabular}

In 1976, an analytical channel response model was developed to describe the temporal characteristics of scattered UV radiation, ${ }^{149)}$ which was further extended to examine angular spectral and path loss in 1979. ${ }^{150)}$ In 2008 and 2010, received BERs with different transmitterreceiver geometries ${ }^{151)}$ and pulse broadening effects in short range NLOS scattering communication channels ${ }^{152)}$ were studied. Besides, optimal combining schemes and maximum likelihood detection schemes were investigated in 2012. ${ }^{153)}$ Additionally, the effects of turbulence and geometries of the system on the received signal energy distribution were studied by L. Liao et al. ${ }^{154)}$

For UWOC, UV scattering enhanced by water molecules, dissolved organic matters and ions makes it feasible to construct underwater UV NLOS communications, which may mitigate the alignment problems caused by turbulence, such as in the presence of bubbles, ${ }^{45)}$ the gradient of salinity and temperature, ${ }^{46)}$ in a UWOC with LOS. An underwater NLOS network concept was proposed by means of back-reflection at the ocean-air interface and a corresponding mathematical 
model was derived. ${ }^{28)}$

In summary, while LOS has achieved significant progress in data rate over long distance, research on NLOS communication requires further efforts. The development and innovation in discrete devices, such as high speed lasers and LEDs, large bandwidth and high responsivity photodetectors, as well as efficient filters with high out-of-band (OOB) rejection will fuel the progress in underwater NLOS communications.

\section{Underwater optical channel models}

Realistic performance evaluation of UWOC systems requires the use of a channel model that accurately reflects the main characteristics of light propagation in underwater environments. According to Mobley, ${ }^{68)}$ such properties can be categorized into two different classes - inherent optical properties (IOPs) and apparent optical properties (AOPs). Inherent optical properties are those depending only on the medium through its composition and do not depend on the geometry of the ambient light field within it. The two fundamental inherent optical properties are the absorption coefficient and the volume scattering function from which the scattering coefficient can be derived. Apparent optical properties, on the other hand, encompass properties that depend on both the medium and the geometric structure of the light field such as diffusion and collimation. ${ }^{155)}$ Inherent optical properties are used to establish link budget and will be the focus of the present survey. Apparent optical properties as well as their reported measurements in the literature can be found in ${ }^{68,155,156)}$. We had also presented our findings in recent Microoptics Conference. ${ }^{157)}$

\subsection{Inherent optical properties}

Propagation of photons in underwater environments is affected by two major processes as described in Section 3.2 - absorption and scattering. Both processes depend on the wavelength of the propagating light. The absorption is characterized by the absorption coefficient $\mathrm{a}(\lambda)$ which corresponds to the amount of absorbed energy at wavelength $\lambda$ per unit of distance and per unit of incident power. The scattering is characterized by the volume scattering function from which the scattering coefficient $b(\lambda)$ can be derived. In general, both processes have detrimental effects on the performance of underwater wireless communication systems. The absorption can result in a significant loss in the light energy, while scattering causes the light to spread, impeding many photons from reaching the receiver. The overall attenuation due to absorption and scattering is 
described by the attenuation coefficient which is the sum of the absorption and scattering coefficients.

$$
c(\lambda)=a(\lambda)+b(\lambda)
$$

Based on measurements, models of the volume scattering coefficients ${ }^{158)}$ and values of absorption and scattering coefficients in different water types have been reported in the literature. ${ }^{22,68)}$ For more details, readers are referred to the recent survey ${ }^{15)}$ and the references therein.

\subsection{Modeling of attenuation in underwater optical channels}

The behavior of light radiance in a propagation medium is described by the radiative transfer equation (RTE). Assuming that both scattered and absorbed photons are completely lost, and neglecting turbulence effects, the light propagation can be described by the Beer-Lambert's law,

$$
I(z)=I_{0} e^{-c(\lambda) z}
$$

where $I_{0}$ is the initial transmit power and $I(z)$ is the light power at distance $z$ from the transmitter. The value of attenuation coefficient $c(\lambda)$ depends on the IOPs of the water which varies widely between geographic locations as reported by several researchers $4,22,25)$ based on the pioneering works of Jerlov ${ }^{159)}$ in the late 1940s and Mobley in the early 1990s ${ }^{68,160)}$, which categorize the world oceans into different water types. Table $\mathrm{V}$ gives the typical values of $a(\lambda), b(\lambda)$, and $c(\lambda)$ for the four major water types.

Table V. Typical values of absorption, scattering and attenuation coefficients for the different ocean water types 25,160 )

\begin{tabular}{|c|c|c|c|}
\hline Water type & $\mathbf{a}(\boldsymbol{\lambda})(/ \mathbf{m})$ & $\mathbf{b}(\boldsymbol{\lambda})(/ \mathbf{m})$ & $\mathbf{c}(\boldsymbol{\lambda})(/ \mathbf{m})$ \\
\hline Pure sea & 0.0405 & 0.0025 & 0.043 \\
\hline Clear ocean & 0.114 & 0.037 & 0.151 \\
\hline Coastal ocean & 0.179 & 0.219 & 0.298 \\
\hline Turbid harbor & 0.266 & 1.824 & 2.19 \\
\hline
\end{tabular}

The above model described by the Beer-Lambert's (BL) law has been attractive for its simplicity, ${ }^{63,161)}$ but it implicitly relies on two unrealistic assumptions. First, it assumes perfect LOS links. Second, it assumes that all scattered photons are lost, which is not realistic as in practice. 
It is known that some photons can still arrive after multiple scattering events. As reported by ${ }^{22,162)}$, in coastal and harbor waters closer to land where the concentration of particulates is high, photons scatter multiple times and may enter the receiver FOV. It was observed that the collected scattered light improves the communication link by reducing receiver's pointing errors. To take into account the collection of multiply scattered events in the propagation of light in turbid water media, Eq. (2) is redefined to include both water optical properties and system parameters such as aperture size, divergence angle and beam radius. ${ }^{22,162)}$

$$
P_{R}(z)=P_{T} e^{-\gamma z}
$$

where $\gamma=a+(1-\eta) b . \eta$ is the scattering factor and defined as the percentage of the collection of scattered light at the receiver and has a value that varies from 0 to 1 . Taking $\omega_{0}=b / c$, Eq. (3) reduces to

$$
P_{R}(z)=P_{T} e^{\left(1-\omega_{0}\right) c z}
$$

Eq. (4) was used to predict underwater link range for a given scenario of water optical properties and system parameters. ${ }^{162)}$ When $c z>15$, the received optical signal is dominated by scattered light and as a result, the over received optical power increases. However, BL still cannot fully describe the channel characteristics of UOWC systems since it only includes range dependence, and cannot address the spatial and temporal properties.

To overcome the limitations of this model and further improve the reliability of UWOC systems, several researchers proposed alternative approaches to solve the RTE without resorting to the simplistic assumptions underlying the Beer-Lambert's Law. The two-dimensional steady state RTE is given as ${ }^{163)}$

$$
\vec{n} . \nabla I(\lambda, \vec{r}, \vec{n})=-c I(\lambda, \vec{r}, \vec{n})+b \int_{2 \pi} \tilde{\beta}(\theta) I(\lambda, \vec{r}, \vec{n}) d \overrightarrow{n^{\prime}}+S(\lambda, \vec{r}, \vec{n})
$$

where $\vec{n}$ is the direction vector, $I(t, \vec{r}, \vec{n})$ is the light radiance, $\nabla$ is the divergence operator, $\mathrm{c}$ is the speed of light in water, $\tilde{\beta}$ is the scattering phase function (SPF)volume scattering function, and $S(\vec{r}, \vec{n})$ is the source radiance, and $\theta$ is the plane scatter angle between direction $\vec{n}$ and $\overrightarrow{n^{\prime}}$ which ranges from $(0,2 \pi)$.

Since it is in general not possible to find an analytical solution for RTE, approximate approaches 
have been proposed. They can be classified into two groups: deterministic approaches and probabilistic approaches. Deterministic approaches rely on numerical approximations and have mainly been proposed in Refs ${ }^{164,165)}$. On the other hand, probabilistic approaches based on Monte Carlo simulations have been advocated, mainly due to their easy programming along with their flexibility. ${ }^{24,166-168)}$ It has been recognized, however, that they are in general time-consuming, requiring the tracking of as much as millions of photons to accurately mimic realistic underwater optical channels.

\subsection{Models of turbulence in underwater channels}

The majority of studies investigating underwater optical channel models have essentially focused on accurately characterizing the scattering and absorption processes described by the RTE. The impact of turbulence has often been overlooked. This becomes problematic because turbulence, caused essentially by rapid changes in the water refractive index, can in practice cause severe degradation in the receiver power at a larger scale than absorption and scattering. To fill this gap, several works, motivated by the analogy with atmospheric optical turbulence, proposed to adopt variations of existing models for classical atmospheric channels. In this vein, the log-normal distribution, already used to characterize turbulence-induced fading in free-space optical channels under weak turbulence regime, has been presented to model weak oceanic turbulence with the probability density function. ${ }^{169,170)}$

$$
f_{I}(I)=\frac{1}{\sqrt{2 \pi} \sigma_{t} I} \exp \left(-\frac{(\ln (I)-\mu)^{2}}{2 \sigma_{t}^{2}}\right)
$$

where $I$ is the received irradiance, $\mu$ is the mean logarithmic light intensity, and $\sigma_{t}^{2}$ refers to the scintillation index. However, several recent works rightly criticized this model, arguing that the variations of the refractive index in the atmosphere caused by temperature and pressure is not the same as those caused by variations of salinity and temperature in water. This fact has recently been proven by a series of recent experimental results in ${ }^{45-47,171)}$, studying respectively the impact of air bubbles, and inhomogeneous salinity and temperature.

4.3.1 Underwater optical channel model in the presence of air bubbles In oceans, there are three types of air bubbles depending on their sources. ${ }^{172)}$ Bubbles could be either of atmospheric, benthic or cavitation sources. Benthic bubbles include common gases such as 
methane and carbon dioxide that escape from the seafloor. Small water vapors generated by ship propellers are examples of cavitation bubbles which are the by-product of man's activities in the ocean. Atmospheric air bubbles are produced by breaking surface waves and rain ${ }^{172,173)}$ and are found to significantly enhance the scattering process therein. ${ }^{174)}$ The influence of air bubbles has been characterized in several previous works based on Mie scattering theory. ${ }^{174,175)}$ It was only recently that the impact of bubbles on the distribution of the irradiance has been investigated through a set of laboratory experiments. ${ }^{47,171)}$ These works essentially show that in the presence of air bubbles the distribution of the irradiance is accurately modeled by a mixture of the exponential distribution and the log-normal distribution which can also be replaced by the Gamma distribution. The presence of the log-normal distribution or equivalently the Gamma distribution agrees with previous studies suggesting its use to model underwater optical channels. The exponential distribution, is however, less common. As shown in ${ }^{47}$ ), it is used to model the loss in the received energy caused by air bubbles. ${ }^{47,171)}$ Moreover, the use of Gamma distribution instead of the log-normal in the mixture model has been found to achieve a slightly higher accuracy. ${ }^{47)}$ The Gamma-exponential mixture model thus becomes more attractive, knowing that from a performance analysis point of view, the Gamma distribution is much more tractable. According to this model, the distribution of the irradiance can be expressed as

$$
f_{I}(I)=\frac{\omega}{\lambda} \exp \left(-\frac{I}{\lambda}\right)+(1-\omega) I^{\alpha-1} \frac{\exp \left(-\frac{I}{\beta}\right)}{\beta^{\alpha} \Gamma(\alpha)} \quad \lambda, \alpha, \beta, I>0,
$$

where $\omega$ is the mixture coefficient, $\lambda$ is the parameter of the exponential distribution, and $\alpha$ and $\beta$ stand for the shape and scale parameters of the Gamma distribution, respectively. The scintillation index $\sigma_{t}^{2}$, defined as the normalized variance of the irradiance $\sigma_{t}{ }^{2}=\frac{\mathrm{E}\left[I^{2}\right]-(\mathrm{E}[I])^{2}}{(\mathrm{E}[I])^{2}}$, is given by

$$
\sigma_{t}^{2}=2 \omega \lambda^{2}+(1-\omega) \alpha \beta^{2}(1+\alpha)-1
$$

It essentially quantifies the strength of the turbulence, taking high values for strongly turbulent channels and low values for weakly turbulent ones. Based on experimental results, the expectationmaximization (EM) algorithm has been applied in ${ }^{47)}$ to obtain maximum likelihood estimates of the model parameters in Eq. (7) under uniform temperature, different salinity conditions, and for various levels of air bubbles.

Figure 9 illustrates the histogram of the experimental data associated with fresh water for a 
bubble level equal to $7.1 \mathrm{~L} / \mathrm{min}$, along with the PDFs of exponential-Gamma and exponentiallognormal distributions whose parameters are carefully tuned using the EM algorithm. Similar experiments have been carried out in the case of salty water. The scintillation index derived using Eq. (8) was shown to increase with the salinity level, unveiling a stronger turbulence condition.

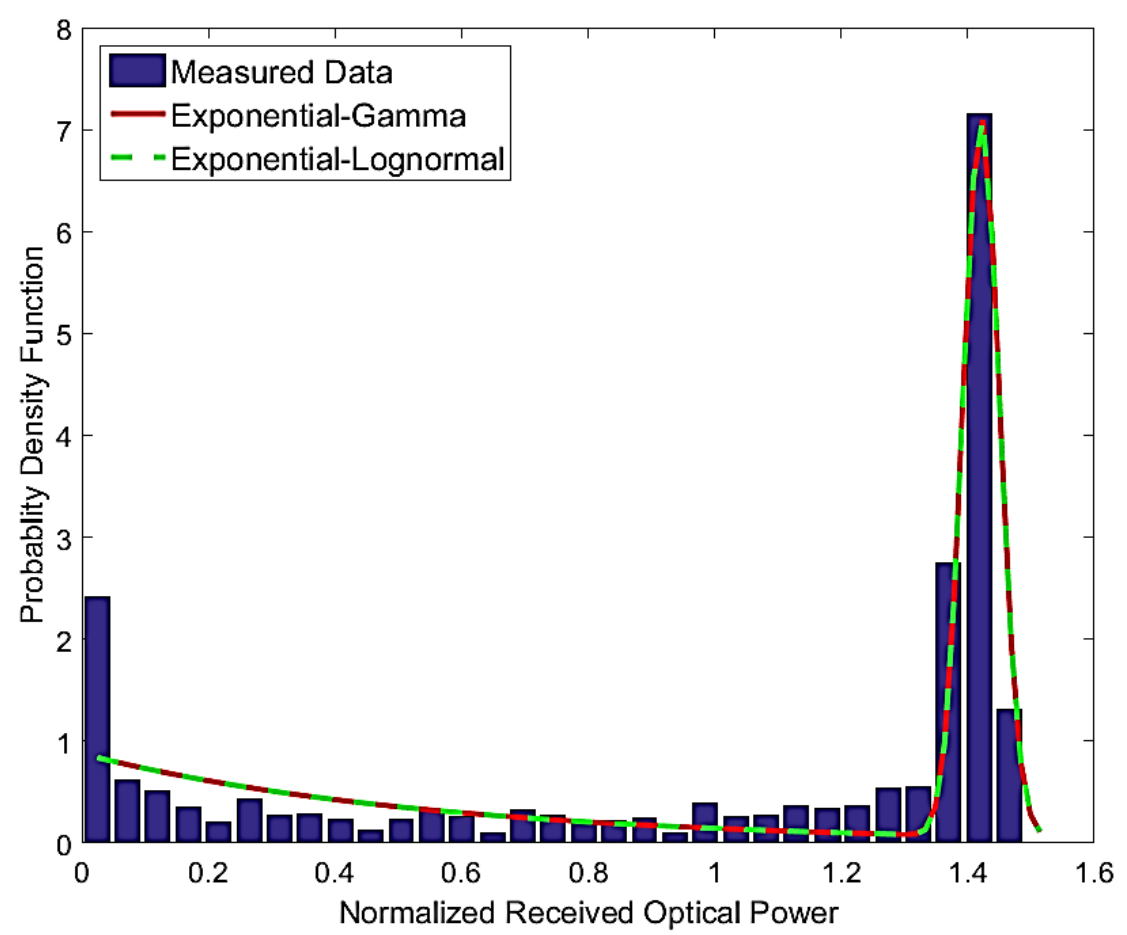

Fig. 9. (Color online) Histogram of the measured data along with the exponential-Gamma and exponential log-normal model for fresh water for a bubble level equal to $7.1 \mathrm{~L} / \mathrm{min}$. (Reprint from ${ }^{47}$ ) 2017 IEEE Global Communications Conference).

\subsubsection{Underwater optical channel model in inhomogeneous salinity Turbulence in} oceans is caused by variations in the refractive index due to fluctuations in temperature and salinity. The presence of salinity gradient in ocean is common. Nature is laden with examples of underwater environments with varying salinity levels. ${ }^{45)}$ This lied behind the motivation of the study by Oubei et al. ${ }^{45)}$ Unlike previous works considering different but uniformly distributed salinity levels, this latter work investigated the impact of salinity gradient on the fluctuations of the irradiance. The salinity gradient in the water channel was created by mixing two water masses of different salinity levels using two identical water buckets. Table VI shows the four different salinity values used to create salinity gradient in the UWOC channel. 
Table VI. Different salinity values used to create salinity gradient in the water channel ${ }^{45)}$

\begin{tabular}{|c|c|c|c|}
\hline $\begin{array}{c}\text { Bucket 1 salinity } \\
(\mathbf{g} / \mathbf{L})\end{array}$ & $\begin{array}{c}\text { Bucket 2 salinity } \\
(\mathbf{g} / \mathbf{L})\end{array}$ & $\begin{array}{c}\text { Channel gradient } \\
\left(\mathbf{g} . \mathbf{L}^{-1} \mathbf{. c m}^{-1}\right)\end{array}$ & $\begin{array}{c}\text { Mean salinity } \\
(\mathbf{g} / \mathbf{L})\end{array}$ \\
\hline 27.5 & 22.5 & 0.05 & \multirow{2}{*}{2} \\
\cline { 1 - 3 } & 20.0 & 0.10 & \multirow{2}{*}{25} \\
\hline 30.0 & 17.5 & 0.15 & \\
\hline 32.5 & 15.0 & 0.20 & \\
\hline
\end{tabular}

Particularly, it was shown that the salinity gradient translates to the distribution of the irradiance presenting a left long tail. As a consequence, the log-normal and the Gamma distribution, known for being right-skewed distributions are not appropriate to model salinity gradients. A more suitable model is the Weibull distribution which was shown to achieve high fitting accuracy. ${ }^{45)}$

Figure 10 illustrates the PDF of the fitted distribution and the corresponding histogram of the measured data for a salinity gradient level equal to $5 \times 10^{-2} \mathrm{~g} \cdot \mathrm{L}^{-1} \cdot \mathrm{cm}^{-1}$. As clearly shown in this figure, the Weibull distribution predicts well the salinity induced light intensity fluctuations in seawater.

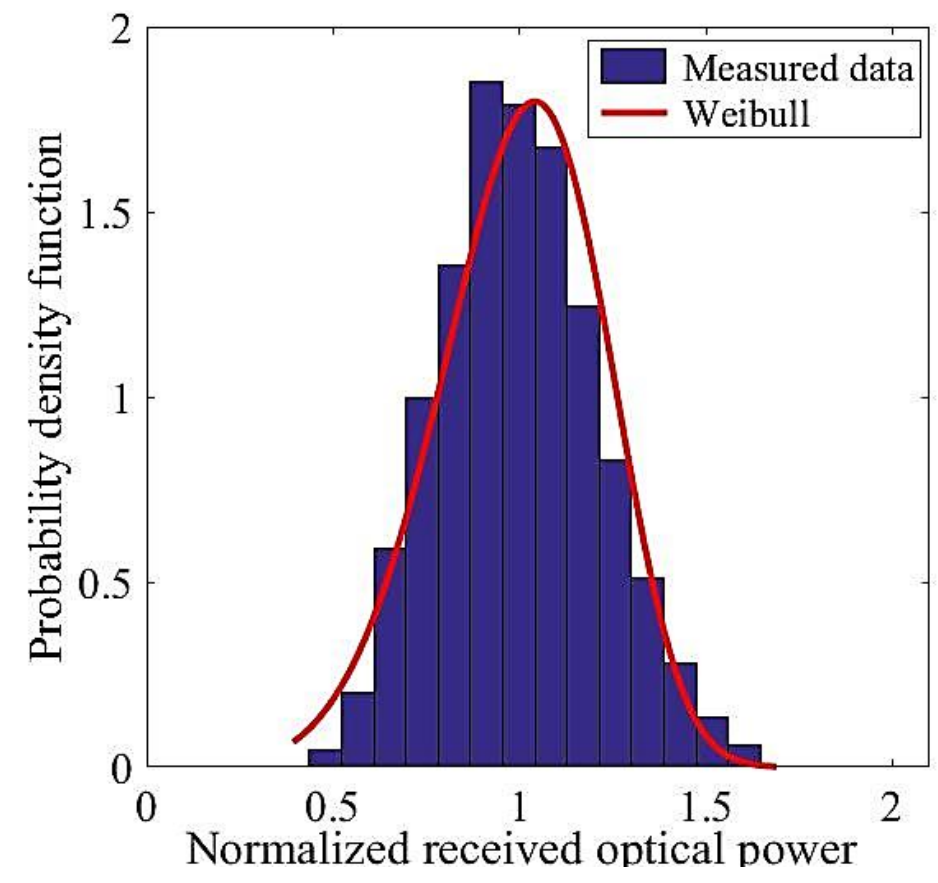

Fig. 10. (Color online) Salinity gradient $=5 \times 10^{-2} \mathrm{~g} \cdot \mathrm{L}^{-1} \mathrm{~cm}^{-1}, \sigma_{\mathrm{t} \text {,measured }}^{2}=0.0429, \lambda=1.0844, \mathrm{k}=$ 5.1982, $\sigma_{\mathrm{t}}^{2}=0.0487$. (Reprint from ${ }^{45)}$ ) 
4.3.3 Underwater optical channel model in inhomogeneous temperature Like the salinity-induced turbulence, temperature-induced turbulence in underwater is also very common and has a significantly detrimental effect on the performance of the communication link. There are many sources of temperature gradient in the oceans. Influxes of glacial fresh water, extratropical cyclones, and ocean currents such as Labrador and Gulf Stream ${ }^{176)}$ are a few examples of temperature-induced turbulent UWOC channels. The impact of temperature gradient was experimentally investigated in ${ }^{46}$. Similar to salinity gradient, it was found that the log-normal distribution, traditionally used in atmospheric optical turbulent channels, failed to mimic the statistical behavior of the measured irradiance. A model using the generalized Gamma distribution (GGD) was thus proposed instead to model and describe the statistical properties of weak temperature-induced turbulence. The GGD is a flexible probability distribution and mostly used in reliability modeling and analysis. The PDF of GGD is given by ${ }^{177)}$.

$$
f(I ; a, b, c)=\frac{c^{a c-1}}{b^{a c}} \times \frac{\exp \left(-\left(\frac{I}{b}\right)^{c}\right)}{\Gamma(a)}, I>0, a, b, c>0
$$

where $a$ and $c$ are the shape parameters, $b$ is the scale parameter, and $\Gamma($.$) is the Gamma function.$ Many common probability distributions are subfamilies of the GGD. For instance, by setting $c=$ 1, the GGD becomes the simple Gamma distribution. The Weibull distribution can be expressed as $f(I ; 1, b, c)$ and the exponential distribution as $f(I ; 1, b, 1)$. The scintillation index of the GGD is expressed as

$$
\sigma_{I}^{2}=\frac{\Gamma(a) \Gamma\left(a+\frac{2}{c}\right)}{\Gamma\left(a+\frac{1}{c}\right)^{2}}-1
$$

Intensity fluctuation measurements were carried out by acquiring $100 \mathrm{~K}$ samples from a laboratory oscilloscope connected to a photodetector. It was found GGD accurately fits the measured data under different temperature gradient levels. Figure 11 illustrates the fit of Gamma, Weibull and generalized Gamma distributions with the measured data histograms of four gradient levels. 

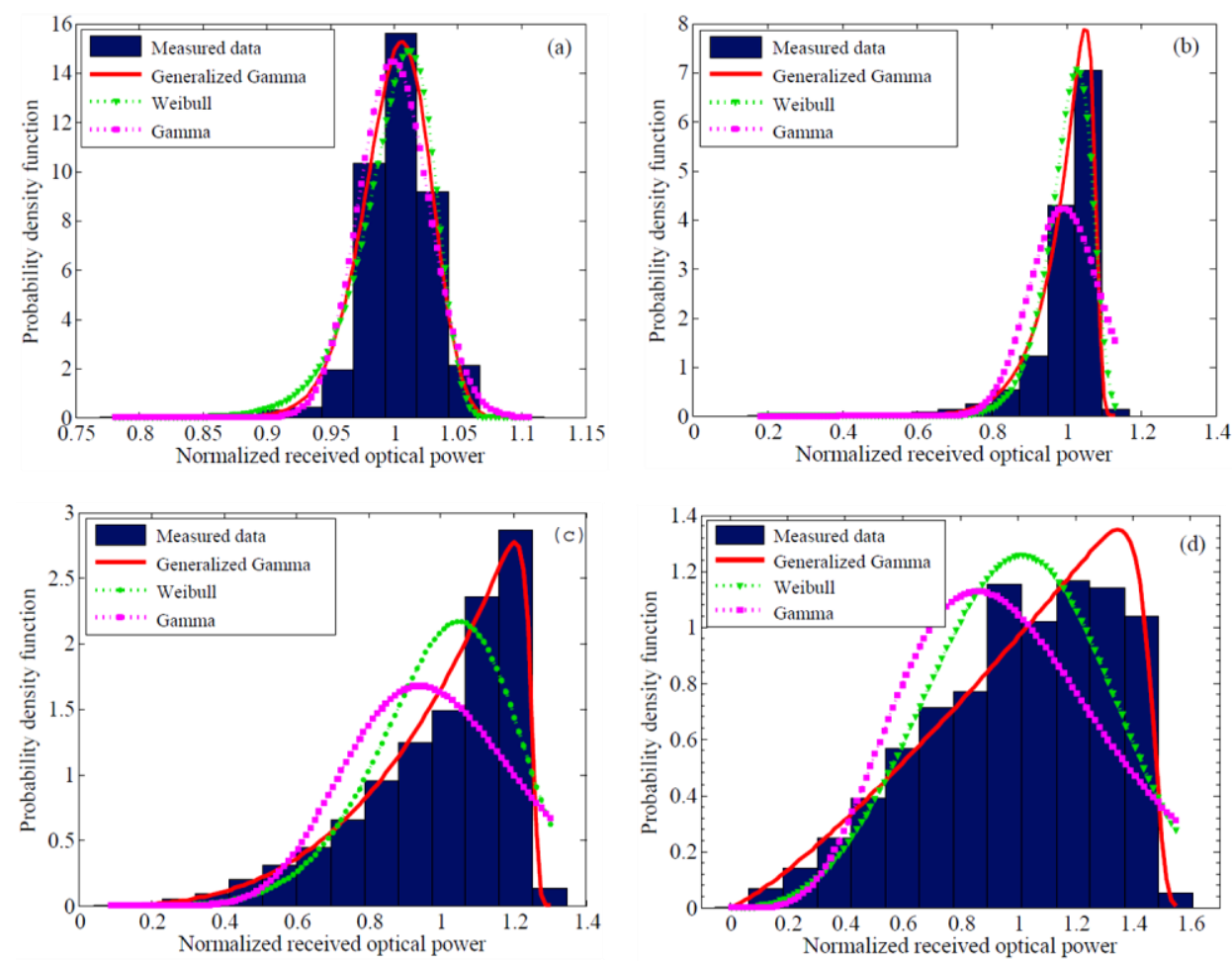

Fig. 11. (Color online) Histograms of the measured data along with the PDF of various distributions under different temperature gradient levels: (a) $0.05^{\circ} \mathrm{C} \cdot \mathrm{cm}^{-1}$, (b) $0.10^{\circ} \mathrm{C} \cdot \mathrm{cm}^{-1}$, (c) $0.15^{\circ} \mathrm{C} \cdot \mathrm{cm}^{-1}$, and (d) $0.20{ }^{\circ} \mathrm{C} \cdot \mathrm{cm}^{-1}$. (Reprint from ${ }^{46)}$. Copyright 2017 Optical Society of America).

\section{Future challenges}

As the preceding sections show, academic and industrial research efforts have already returned UWOC into reality. However, this research area is still in its early stage in many respects and a lot

of open questions need to be addressed. Some future UWOC research challenges are suggested in the following lines.

\section{i. $\quad$ Transmitter technologies}

To circumvent the dynamics nature of the underwater channel which affects the optical signal's overall attenuation, efficient and robust tunable lasers in the violet-blue-green regime need to be developed. In addition, in order to reduce background noise, it would also be interesting to explore the development of a laser with operating wavelength corresponds exactly to one of the Fraunhofer lines in the solar spectrum. ${ }^{178)}$

\section{ii. $\quad$ Detector technologies}

Many underwater platforms are deployed in deep sea and there is a strong need to develop UWOC 
systems with highly efficient photodetectors. Learning from bacterial photosynthesis taking place at ocean depths down to $2000 \mathrm{~m},{ }^{179,180)}$ biologically-inspired quantum photosensors (BQP) have been proposed. ${ }^{181)}$ Photosynthetic organisms such as green sulfur bacteria use sophisticated molecular antenna systems to efficiently collect and process dim light that comes from the solar radiation or hydrothermal vents even at a depth that is totally dark to the human eye. ${ }^{182)}$ The transport of the energy has a quantum effect as experimentally demonstrated by ${ }^{183)}$. Selfassembled J-Aggregates molecules are perfect candidates as they show quantum transport over hundreds of chromophores at room temperature which can be used as antennas to collect light. ${ }^{184,}$ ${ }^{185)}$ Developing devices that mimic this natural photosensing process is crucial as they are expected to surpass the current detection capabilities of APD and PIN detectors with quantum efficiency of nearly $90 \%$ in the blue-green regime. ${ }^{181)}$ Thus, there is a huge research potential for studying and developing more advanced BQP for the next-generation UWOC systems.

\section{iii. Link misalignment}

Link misalignment is one of the challenges of LOS UWOC systems and remains an active research direction. Smart transceivers, $\mathrm{RF} /$ acoustic/optical hybrid systems, and modulating retro-reflectors (MRR) have been proposed to reduce the pointing and tracking requirements of especially moving underwater platforms such as autonomous underwater vehicles (AUVs) and remotely operated vehicles (ROVs). ${ }^{186,187)}$ Deploying and testing smart transceivers and MRR embedded UWOC systems in real underwater environment for misalignment mitigation is thus important.

\section{iv. Transmission schemes}

Multiple-input multiple-output (MIMO) transmission technique has the potential to mitigate major degrading effects of underwater channels such as turbulence-induced fading and physical obstructions. ${ }^{41)}$ MIMO increases the signal-capture power by using several light sources to temporally combine multipath data streams to improve the overall SNR.

\section{v. Channel modeling}

With the recent development of accurate and tractable mathematical models for the underwater turbulence channel, the challenge of UWOC channel modeling is nearly resolved. ${ }^{45-47,171)}$ However, more system level tests including vertical link configurations need to be performed in a realistic underwater environment. 


\section{Conclusions}

Despite the harsh underwater environment, UWOC research has witnessed significant progress in the last few years. In this review paper, after a brief overview of the latest UWOC research, we provided a detailed survey on optical light sources and detection systems. Emphasis is placed on UV-blind and single photon detectors for UWOC applications. We also presented recent advances in UWOC channel modeling based on measured data taking into account the impact of air bubbles, salinity and temperature induced turbulences. The major advantage of these new channel models based on measured data is that they have simple mathematical forms making them attractive from a performance analysis point of view. However, this research area is in early stages and a lot remains to be explored. We believe this survey will provide researchers with a fundamental understanding of UWOC and will serve as a guide for UWOC system engineers.

\section{Acknowledgments}

The financial support from King Abdulaziz City for Science and Technology (KACST), Grant No. KACST TIC R2-FP-008 is gratefully acknowledged. This work was partially supported by the King Abdullah University of Science and Technology (KAUST) baseline funding, BAS/1/161401-01, KAUST funding KCR/1/2081-01-01, and GEN/1/6607-01-01, as well as KAUST-KFUPM Special Initiative (KKI) Program, REP/1/2878-01-01. 


\section{References}

1) B. Truax, Acoustic Communication (Greenwood Publishing Group, 2001).

2) E. M. Sozer, M. Stojanovic and J. G. Proakis, IEEE J. Ocean. Eng. 25, 72 (2000).

3) M. Stojanovic, IEEE J. Ocean. Eng. 21, 125 (1996).

4) F. Hanson and S. Radic, Appl. Opt. 47, 277 (2008).

5) J. R. Apel, Principles of Ocean Physics (Academic Press, Orlando, 1987).

6) M. Kerker, Physical Optics of Ocean Water (Elsevier, 1988) pp. 386.

7) P. Lacovara, Mar. Technol. Soc. J. 42, 93 (2008).

8) G. Baiden, Y. Bissiri and A. Masoti, Ocean Engineering. 36, 633 (2009).

9) K. Nakamura, I. Mizukoshi and M. Hanawa, Opt. Express. 23, 1558 (2015).

10) T.-C. Wu, Y.-C. Chi, H.-Y. Wang, C.-T. Tsai and G.-R. Lin, Sci. Rep. 7, 40480 (2017).

11) M. Kong, W. Lv, T. Ali, R. Sarwar, C. Yu, Y. Qiu, F. Qu, Z. Xu, J. Han and J. Xu, Opt. Express. 25, 20829 (2017).

12) Y.-C. Chi, D.-H. Hsieh, C.-T. Tsai, H.-Y. Chen, H.-C. Kuo and G.-R. Lin, Opt. Express. 23, 13051 (2015).

13) D. Tsonev, H. Chun, S. Rajbhandari, J. J. D. McKendry, S. Videv, E. Gu, M. Haji, S. Watson, A. E. Kelly, G. Faulkner, M. D. Dawson, H. Haas and D. O'Brien, IEEE Photon. Technol. Lett. 26, 637 (2014).

14) M.-A. Khalighi, C. Gabriel, T. Hamza, S. Bourennane, P. Leon and V. Rigaud, 16th International Conference on Transparent Optical Networks (ICTON), 2014, p. 1.

15) Z. Zeng, S. Fu, H. Zhang, Y. Dong and J. Cheng, IEEE Commun. Surv. Tutor. 19, 204 (2017).

16) D. Arnush, J. Opt. Soc. Am. 62, 1109 (1972).

17) S. Karp, IEEE Trans. Commun. 24, 66 (1976).

18) J. B. Snow, J. P. Flatley, D. E. Freeman, M. A. Landry, C. E. Lindstrom, J. R. Longacre and J. A. Schwartz, Ocean Optics XI, 1992, p. 419.

19) N. Farr, A. Chave, L. Freitag, J. Preisig, S. White, D. Yoerger and P. Titterton, Proc. MTS/IEEE OCEANS, 2005, p. 928.

20) N. Farr, A. Bowen, J. Ware, C. Pontbriand and M. Tivey, IEEE OCEANS, 2010, p. 1.

21) A. Laux, R. Billmers, L. Mullen, B. Concannon, J. Davis, J. Prentice and V. Contarino, J. Mod. Opt. 49, 439 (2002).

22) B. M. Cochenour, L. J. Mullen and A. E. Laux, IEEE J. Ocean. Eng. 33, 513 (2008).

23) L. Mullen, B. Cochenour, W. Rabinovich, R. Mahon and J. Muth, Appl. Opt. 48, 328 (2009).

24) C. Gabriel, M. A. Khalighi, S. Bourennane, P. Leon and V. Rigaud, IEEE J. Opt. Commun. Netw. 5, 1 (2013).

25) W. Cox and J. Muth, J. Opt. Soc. Am. A. 31, 920 (2014).

26) W. W. Hou, Opt. Lett. 34, 2688 (2009).

27) S. Arnon, Opt. Eng. 49, 015001 (2010).

28) S. Arnon and D. Kedar, J. Opt. Soc. Am. A. 26, 530 (2009).

29) H. M. Oubei, R. T. ElAfandy, K.-H. Park, T. K. Ng, M.-S. Alouini and B. S. Ooi, IEEE Photon. J. 9, 1 (2017).

30) H. M. Oubei, C. Li, K.-H. Park, T. K. Ng, M.-S. Alouini and B. S. Ooi, Opt. Express. 23, 20743 (2015).

31) O. Graydon, Nat. Photonics. 9, 707 (2015).

32) C. Shen, Y. Guo, H. M. Oubei, T. K. Ng, G. Liu, K.-H. Park, K.-T. Ho, M.-S. Alouini and B. S. Ooi, Opt. Express. 24, 25502 (2016).

33) P. Tian, X. Liu, S. Yi, Y. Huang, S. Zhang, X. Zhou, L. Hu, L. Zheng and R. Liu, Opt. Express. 25, 1193 (2017).

34) Y. Chen, M. Kong, T. Ali, J. Wang, R. Sarwar, J. Han, C. Guo, B. Sun, N. Deng and J. Xu, Opt. Express. 25, 14760 (2017).

35) M. Kong, J. Wang, Y. Chen, T. Ali, R. Sarwar, Y. Qiu, S. Wang, J. Han and J. Xu, Opt. Express. 25, 21509 (2017).

36) H. M. Oubei, J. R. Duran, B. Janjua, H.-Y. Wang, C.-T. Tsai, Y.-C. Chi, T. K. Ng, H.-C. Kuo, J.-H. He and M.-S. Alouini, Opt. Express. 23, 23302 (2015).

37) J. Xu, M. Kong, A. Lin, Y. Song, X. Yu, F. Qu, J. Han and N. Deng, Opt. Commun. 369, 100 (2016).

38) J. Baghdady, K. Miller, K. Morgan, M. Byrd, S. Osler, R. Ragusa, W. Li, B. M. Cochenour and E. G. Johnson, Opt. Express. 24, 9794 (2016).

39) C. Kai, P. Huang, F. Shen, H. Zhou and Z. Guo, IEEE Photon. J. 9, 1 (2017).

40) Y. Song, W. Lu, B. Sun, Y. Hong, F. Qu, J. Han, W. Zhang and J. Xu, Opt. Commun. 403, 205 (2017).

41) M. V. Jamali, J. A. Salehi and F. Akhoundi, IEEE Trans. Commun. 65, 1176 (2017).

42) Y. F. Huang, C. T. Tsai, Y. C. Chi, D. W. Huang and G. R. Lin, J. Lightwave Technol. 36, 1 (2017). 
43) X. Liu, S. Yi, X. Zhou, Z. Fang, Z.-J. Qiu, L. Hu, C. Cong, L. Zheng, R. Liu and P. Tian, Opt. Express. 25, 27937 (2017).

44) M. V. Jamali, P. Khorramshahi, A. Tashakori, A. Chizari, S. Shahsavari, S. AbdollahRamezani, M. Fazelian, S. Bahrani and J. A. Salehi, Iran Workshop on Communication and Information Theory (IWCIT), 2016, p. 1.

45) H. Makine Oubei, E. Zedini, R. T. ElAfandy, A. Kammoun, T. K. Ng, M.-S. Alouini and B. S. Ooi, 12th Conference on Lasers and Electro-Optics Pacific Rim (CLEO-PR), 2017, p. 1.

46) H. M. Oubei, E. Zedini, R. T. ElAfandy, A. Kammoun, M. Abdallah, T. K. Ng, M. Hamdi, M.-S. Alouini and B. S. Ooi, Opt. Lett. 42, 2455 (2017).

47) E. Zedini, H. M. Oubei, A. Kammoun, M. Hamdi, B. S. Ooi and M. S. Alouini, IEEE Global Communications Conference (GLOBECOM), 2017, p. 1.

48) S. Watson, M. Tan, S. P. Najda, P. Perlin, M. Leszczynski, G. Targowski, S. Grzanka and A. Kelly, Opt. Lett. 38, 3792 (2013).

49) C. Lee, C. Zhang, M. Cantore, R. M. Farrell, S. H. Oh, T. Margalith, J. S. Speck, S. Nakamura, J. E. Bowers and S. P. DenBaars, Opt. Express. 23, 16232 (2015).

50) B. Janjua, H. M. Oubei, J. R. D. Retamal, T. K. Ng, C.-T. Tsai, H.-Y. Wang, Y.-C. Chi, H.-C. Kuo, G.-R. Lin, J.-H. He, and B. S. Ooi, Opt. Express 23, 18746 (2015)

51) C. Lee, C. Zhang, D. L. Becerra, S. Lee, C. A. Forman, S. H. Oh, R. M. Farrell, J. S. Speck, S. Nakamura and J. E. Bowers, Appl. Phys. Lett. 109, 101104 (2016).

52) C. Shen, J. T. Leonard, E. C. Young, T. K. Ng, S. P. DenBaars, J. S. Speck, S. Nakamura, A. Y. Alyamani, M. M. El-Desouki and B. S. Ooi, CLEO: Science and Innovations, 2016, p. STh1L. 2.

53) C. Shen, T. K. Ng, Y. Yang, D. Cha and B. S. Ooi, IEEE Photonics Conference, 2013, p. 174.

54) K. A. Denault, M. Cantore, S. Nakamura, S. P. DenBaars and R. Seshadri, AIP Adv. 3, 072107 (2013).

55) C. Lee, C. Shen, H. M. Oubei, M. Cantore, B. Janjua, T. K. Ng, R. M. Farrell, M. M. El-Desouki, J. S. Speck, S. Nakamura, B. S. Ooi and S. P. DenBaars, Opt. Express. 23, 29779 (2015).

56) I. Dursun, C. Shen, M. R. Parida, J. Pan, S. P. Sarmah, D. Priante, N. Alyami, J. Liu, M. I. Saidaminov, M. S. Alias, A. L. Abdelhady, T. K. Ng, O. F. Mohammed, B. S. Ooi and O. M. Bakr, ACS Photonics. 3, 1150 (2016).

57) J. J. Wierer, J. Y. Tsao and D. S. Sizov, Laser Photonics Rev. 7, 963 (2013).

58) M. Cantore, N. Pfaff, R. M. Farrell, J. S. Speck, S. Nakamura and S. P. DenBaars, Opt. Express. 24, A215 (2016).

59) Y. H. Song, E. K. Ji, B. W. Jeong, M. K. Jung, E. Y. Kim and D. H. Yoon, Sci. Rep. 6 (2016).

60) D. Tsonev, S. Videv and H. Haas, Opt. Express. 23, 1627 (2015).

61) D. Karunatilaka, F. Zafar, V. Kalavally and R. Parthiban, IEEE Commun. Surv. Tutor. 17, 1649 (2015).

62) C. Lee, C. Shen, C. Cozzan, R. M. Farrell, J. S. Speck, S. Nakamura, B. S. Ooi and S. P. DenBaars, Opt. Express. 25, 17480 (2017).

63) J. H. Smart, IEEE Military Communications Conference (MILCOM), 2005, p. 1140.

64) F. M. Sogandares and E. S. Fry, Appl. Opt. 36, 8699 (1997).

65) R. M. Pope and E. S. Fry, Appl. Opt. 36, 8710 (1997).

66) M. N. Berberan-Santos, J. Chem. Educ. 67, 757 (1990).

67) W. C. Cox, M. S., A 1 Mbps Underwater Communication System Using a $405 \mathrm{~nm}$ Laser Diode and Photomultiplier Tube, North Carolina State University (2007).

68) C. Mobley, Light and Water: Radiative Transfer in Natural Waters (Academic Press, 1994).

69) T. J. Petzold, Volume Scattering Functions for Selected Ocean Waters (UC San Diego, 1972) p. 77.

70) S. Q. Duntley, Underwater Lighting by Submerged Lasers and Incandescent Sources (Defense Technical Information Center, 1971).

71) B. Cochenour, S. P. O'Connor and L. J. Mullen, Opt. Eng. 53, 8 (2013).

72) B. Cochenour and L. J. Mullen, Free-space Optical Communication Underwater (Cambridge University Press, 2012).

73) C. Shen, Light, Energy and the Environment, 2017, p. SW3C.2.

74) C. Shen, T. K. Ng, C. Lee, J. T. Leonard, S. Nakamura, J. S. Speck, S. P. Denbaars, A. Y. Alyamani, M. M. El-Desouki and B. S. Ooi, SPIE OPTO, 2017, p. 10.

75) C. Shen, T. K. Ng, J. T. Leonard, A. Pourhashemi, S. Nakamura, S. P. DenBaars, J. S. Speck, A. Y. Alyamani, M. M. El-desouki and B. S. Ooi, Opt. Lett. 41, 2608 (2016).

76) C. Shen, C. Lee, T. K. Ng, S. Nakamura, J. S. Speck, S. P. DenBaars, A. Y. Alyamani, M. M. El-Desouki and B. S. Ooi, Opt. Express. 24, 20281 (2016).

77) M. Feng, J. Wang, R. Zhou, Q. Sun, H. Gao, Y. Zhou, J. Liu, Y. Huang, S. Zhang, M. Ikeda, H. Wang, Y. 
78) Z. Y. Jiang, M. R. M. Atalla, G. J. You, L. Wang, X. Y. Li, J. Liu, A. M. Elahi, L. Wei and J. Xu, Opt. Lett. 39, 5657 (2014).

79) C. Shen, T. K. Ng, J. T. Leonard, A. Pourhashemi, H. M. Oubei, M. S. Alias, S. Nakamura, S. P. DenBaars, J. S. Speck, A. Y. Alyamani, M. M. Eldesouki and B. S. Ooi, ACS Photonics. 3, 262 (2016).

80) C. Shen, C. Lee, T. K. Ng, J. S. Speck, S. Nakamura, S. P. DenBaars, A. Y. Alyamani, M. M. Eldesouki and B. S. Ooi, IEEE Photonics Conference (IPC), 2016, p. 813.

81) C. Shen, T. K. Ng, C. Lee, S. Nakamura, J. S. Speck, S. P. DenBaars, A. Y. Alyamani, M. M. El-Desouki, and B. S. Ooi, Opt. Express, 26, A219 (2018).

82) K.-T. Ho, R. Chen, G. Liu, C. Shen, J. Holguin-Lerma, A. A. Al-Saggaf, T. K. Ng, M.-S. Alouini, J.-H. He and B. S. Ooi, Opt. Express. 26, 3037 (2018).

83) C. Shen, C. Lee, E. Stegenburgs, J. H. Lerma, T. K. Ng, S. Nakamura, S. P. DenBaars, A. Y. Alyamani, M. M. El-Desouki and B. S. Ooi, Appl. Phys. Express. 10, 042201 (2017).

84) M. Tchernycheva, A. Messanvi, A. de Luna Bugallo, G. Jacopin, P. Lavenus, L. Rigutti, H. Zhang, Y. Halioua, F. H. Julien, J. Eymery and C. Durand, Nano Lett. 14, 3515 (2014).

85) W. Cai, Y. Yang, X. Gao, J. Yuan, W. Yuan, H. Zhu and Y. Wang, Opt. Express. 24, 6004 (2016).

86) J. D. Mason, M. T. Cone and E. S. Fry, Appl. Opt. 55, 7163 (2016).

87) E. Monroy, F. Omnes and F. Calle, Semicond. Sci. Technol. 18, R33 (2003).

88) A. BenMoussa, A. Soltani, U. Schuhle, K. Haenen, Y. M. Chong, W. J. Zhang, R. Dahal, J. Y. Lin, H. X. Jiang, H. A. Barkad, B. BenMoussa, D. Bolsee, C. Hermans, U. Kroth, C. Laubis, V. Mortet, J. C. De Jaeger, B. Giordanengo, M. Richter, F. Scholze and J. F. Hochedez, Diam. Relat. Mater. 18, 860 (2009).

89) D. Renker and E. Lorenz, J. Instrum. 4, P04004 (2009).

90) L. Sang, M. Liao and M. Sumiya, Sensors. 13, 10482 (2013).

91) D.-S. Tsai, W.-C. Lien, D.-H. Lien, K.-M. Chen, M.-L. Tsai, D. G. Senesky, Y.-C. Yu, A. P. Pisano and J.-H. He, Sci. Rep. 3, 2628 (2013).

92) Z. Alaie, S. M. Nejad and M. Yousefi, Mater. Sci. Semicond. Process. 29, 16 (2015).

93) T. Detchprohm, X. Li, S. C. Shen, P. D. Yoder and R. D. Dupuis, Chapter Four - III-N Wide Bandgap DeepUltraviolet Lasers and Photodetectors Semiconductors and Semimetals (Elsevier, 2017) pp. 121.

94) M. A. Khan, M. Shatalov, H. Maruska, H. Wang and E. Kuokstis, Jpn. J. Appl. Phys. 44, 7191 (2005).

95) S. Fujita, Jpn. J. Appl. Phys. 54, 030101 (2015).

96) J. C. Carrano, T. Li, D. L. Brown, P. A. Grudowski, C. J. Eiting, R. D. Dupuis and J. C. Campbell, Appl. Phys. Lett. 73, 2405 (1998).

97) A. Osinsky, S. Gangopadhyay, B. W. Lim, M. Z. Anwar, M. A. Khan, D. V. Kuksenkov and H. Temkin, Appl. Phys. Lett. 72, 742 (1998).

98) C. Pernot, A. Hirano, M. Iwaya, T. Detchprohm, H. Amano and I. Akasaki, Jpn. J. Appl. Phys. 39, L387 (2000).

99) T. Tut, N. Biyikli, I. Kimukin, T. Kartaloglu, O. Aytur, M. S. Unlu and E. Ozbay, Solid·State Electron. 49, 117 (2005).

100) T. Tut, T. Yelboga, E. Ulker and E. Ozbay, Appl. Phys. Lett. 92, 103502 (2008).

101) S. Rathkanthiwar, A. Kalra, S. V. Solanke, N. Mohta, R. Muralidharan, S. Raghavan and D. N. Nath, J. Appl. Phys. 121, 164502 (2017).

102) A. Soltani, H. A. Barkad, M. Mattalah, B. Benbakhti, J. C. De Jaeger, Y. M. Chong, Y. S. Zou, W. J. Zhang, S. T. Lee, A. BenMoussa, B. Giordanengo and J. F. Hochedez, Appl. Phys. Lett. 92, 053501 (2008).

103) H. Srour, J. P. Salvestrini, A. Ahaitouf, S. Gautier, T. Moudakir, B. Assouar, M. Abarkan, S. Hamady and A. Ougazzaden, Appl. Phys. Lett. 99, 221101 (2011).

104) T. C. Doan, J. Li, J. Y. Lin and H. X. Jiang, AIP Adv. 6, 075213 (2016).

105) C. Soci, A. Zhang, B. Xiang, S. A. Dayeh, D. P. R. Aplin, J. Park, X. Y. Bao, Y. H. Lo and D. Wang, Nano Lett. 7, 1003 (2007).

106) M. Nakano, T. Makino, A. Tsukazaki, K. Ueno, A. Ohtomo, T. Fukumura, H. Yuji, S. Akasaka, K. Tamura, K. Nakahara, T. Tanabe, A. Kamisawa and M. Kawasaki, Appl. Phys. Lett. 93, 123309 (2008).

107) J. Du, J. Xing, C. Ge, H. Liu, P. Liu, H. Hao, J. Dong, Z. Zheng and H. Gao, J. Phys. D: Appl. Phys. 49, 425105 (2016).

108) A. Singh Pratiyush, S. Krishnamoorthy, S. Vishnu Solanke, Z. Xia, R. Muralidharan, S. Rajan and D. N. Nath, Appl. Phys. Lett. 110, 221107 (2017).

109) B. Zhao, F. Wang, H. Chen, L. Zheng, L. Su, D. Zhao and X. Fang, Adv. Funct. Mater. 27 (2017).

110) L. K. Wang, Z. G. Ju, C. X. Shan, J. Zheng, D. Z. Shen, B. Yao, D. X. Zhao, Z. Z. Zhang, B. H. Li and J. Y. 
Zhang, Solid State Commun. 149, 2021 (2009).

111) Y. N. Hou, Z. X. Mei, H. L. Liang, D. Q. Ye, S. Liang, C. Z. Gu and X. L. Du, Appl. Phys. Lett. 98, 263501 (2011).

112) Z. Yongdan, Z. Hai, F. Guojia and L. Meiya, Semicond. Sci. Technol. 27, 065003 (2012).

113) Y. Guo, C. Liu, H. Tanaka and E. Nakamura, J. Phys. Chem. Lett. 6, 535 (2015).

114) J. C. Carrano, T. Li, C. J. Eiting, R. D. Dupuis and J. C. Campbell, J. Electron. Mater. 28, 325 (1999).

115) C. Collins, U. Chowdhury, M. Wong, B. Yang, A. Beck, R. Dupuis and J. Campbell, Appl. Phys. Lett. 80, 3754 (2002).

116) S. N. Mohammad, Solid·State Electron. 46, 203 (2002).

117) R. H. Hadfield, Nat. Photonics. 3, 696 (2009).

118) P. A. Hiskett and R. A. Lamb, Proc. SPIE. 9114, 91140P (2014).

119) Y. Li, S. Videv, M. Abdallah, K. Qaraqe, M. Uysal and H. Haas, IEEE Global Communications Conference (GLOBECOM), 2014, p. 2108.

120) T. Shafique, O. Amin, M. Abdallah, I. S. Ansari, M. S. Alouini and K. Qaraqe, IEEE Photon. J. 9, 7906313 (2017).

121) C. Wang, H.-Y. Yu and Y.-J. Zhu, IEEE Photon. J. 8, 7906311 (2016).

122) E. A. Dauler, B. S. Robinson, A. J. Kerman, V. Anant, R. J. Barron, K. K. Berggren, D. O. Caplan, J. J. Carney, S. A. Hamilton, K. M. Rosfjord, M. L. Stevens and J. K. W. Yang, Proc. SPIE. 6372, 637212 (2006).

123) M. D. Eisaman, J. Fan, A. Migdall and S. V. Polyakov, Rev. Sci. Instrum. 82, 071101 (2011).

124) A. A. Verevkin, J. Zhang, W. Slysz, R. Sobolewski, A. P. Lipatov, O. Okunev, G. Chulkova, A. Korneev and G. N. Gol'tsman, International Symposium on Optical Science and Technology, 2002, p. 8.

125) E. A. Dauler, M. E. Grein, A. J. Kerman, F. Marsili, S. Miki, S. W. Nam, M. D. Shaw, H. Terai, V. B. Verma and T. Yamashita, Opt. Eng. 53, 081907 (2014).

126) V. B. Verma, B. Korzh, F. Bussières, R. D. Horansky, S. D. Dyer, A. E. Lita, I. Vayshenker, F. Marsili, M. D. Shaw, H. Zbinden, R. P. Mirin and S. W. Nam, Opt. Express. 23, 33792 (2015).

127) D. H. Slichter, V. B. Verma, D. Leibfried, R. P. Mirin, S. W. Nam and D. J. Wineland, Opt. Express. 25, 8705 (2017).

128) D. Rosenberg, A. J. Kerman, R. J. Molnar and E. A. Dauler, Opt. Express. 21, 1440 (2013).

129) A. Casaburi, A. Pizzone and R. H. Hadfield, Fotonica AEIT Italian Conference on Photonics Technologies, 2014, p. 06843851.

130) C. J. Chunnilall, I. P. Degiovanni, S. Kück, I. Müller and A. G. Sinclair, Opt. Eng. 53, 081910 (2014).

131) T. Shigeki, Jpn. J. Appl. Phys. 53, 030101 (2014).

132) O. Thomas, Z. L. Yuan, J. F. Dynes, A. W. Sharpe and A. J. Shields, Appl. Phys. Lett. 97, 031102 (2010).

133) M. Ghioni, G. Armellini, P. Maccagnani, I. Rech, M. K. Emsley and M. S. Ünlü, J. Mod. Opt. 56, 309 (2009).

134) J. C. Blakesley, P. See, A. J. Shields, B. E. Kardynał, P. Atkinson, I. Farrer and D. A. Ritchie, Phys. Rev. Lett. 94, 067401 (2005).

135) L. Redaelli, G. Bulgarini, S. Dobrovolskiy, S. N. Dorenbos, V. Zwiller, E. Monroy and J. M. Gérard, Supercon. Sci. Technol. 29, 065016 (2016).

136) L. Ji, J. Gao, A.-L. Yang, Z. Feng, X.-F. Lin, Z.-G. Li and X.-M. Jin, Opt. Express. 25, 19795 (2017).

137) F. Zheng, R. Xu, Y. Chen, G. Zhu, B. Jin, W. Xu, J. Chen and P. Wu, IEEE Photon. J. 9, 4502108 (2017).

138) T. B. H. Tentrup, T. Hummel, T. A. W. Wolterink, R. Uppu, A. P. Mosk and P. W. H. Pinkse, Opt. Express. 25, 2826 (2017).

139) S. A. Hamilton, C. E. DeVoe, A. S. Fletcher, I. D. Gaschits, F. Hakimi, N. D. Hardy, T. Howe, N. Mittleman, H. G. Rao and M. S. Scheinbart, Ocean Sensing and Monitoring IX, 2017, p. 1018606.

140) Z. Xu and B. M. Sadler, IEEE Commun. Mag. 46 (2008).

141) X. Sun, Z. Zhang, A. Chaaban, T. K. Ng, C. Shen, R. Chen, J. Yan, H. Sun, X. Li and J. Wang, Opt. Express. 25, 23267 (2017).

142) G. L. Harvey, A Survey of Ultraviolet Communication Systems (Defense Technical Information Center, 1964).

143) D. E. Sunstein, A Scatter Communications Link at Ultraviolet Frequencies, Massachusetts Institute of Technology (1968).

144) E. S. Fishburne, M. E. Neer and G. Sandri, Voice Communication Via Scattered Ultraviolet Radiation (1976).

145) J. J. Puschell and R. Bayse, Proc. Tactical Communications Conference, 1990, p. 253.

146) M. Geller, T. E. Keenan, D. E. Altman and R. H. Patterson, US4493114A (1985).

147) T. Feng, F. Xiong, Q. Ye, Z. Pan, Z. Dong and Z. Fang, Asia-Pacific Optical Communications, 2007, p. 7.

148) D. Han, Y. Liu, K. Zhang, P. Luo and M. Zhang, Opt. Express. 20, 15833 (2012).

149) D. M. Reilly, Atmospheric Optical Communications in the Middle Ultraviolet, Massachusetts Institute of 
Technology (1976).

150) D. M. Reilly and C. Warde, J. Opt. Soc. Am. 69, 464 (1979).

151) G. Chen, F. Abou-Galala, Z. Xu and B. M. Sadler, Opt. Express. 16, 15059 (2008).

152) G. Chen, Z. Xu and B. M. Sadler, Opt. Express. 18, 10500 (2010).

153) H. Xiao, Y. Zuo, J. Wu, Y. Li and J. Lin, Opt. Lett. 37, 4143 (2012).

154) L. Liao, Z. Li, T. Lang, B. M. Sadler, and G. Chen, Proc. SPIE 9224, 92241A (2014).

155) L. J. Johnson, F. Jasman, R. J. Green and M. S. Leeson, Underw. Technol. 32, 167 (2014).

156) R. E. Green and H. M. Sosik, J. Geophys. Res. 109 (2004).

157) H. M. Oubei, C. Shen, K. H. Park, A. Kammoun, T. K. Ng, M. S. Alouini and B. S. Ooi, 22nd Microoptics Conference (MOC), 2017, p. 34.

158) C. Mobley, E. Boss and C. Roesler, Ocean Optics Web Book (2010).

159) N. G. Jerlov and F. F. Koczy, Photographic Measurements of Daylight in Deep Water (Elanders boktr., 1951).

160) C. Mobley, Opt. \& Phot. News 2,14 (1991).

161) J. W. Giles and I. N. Bankman, IEEE Military Communications Conference (MILCOM), 2005, p. 1700.

162) B. Cochenour, L. Mullen and J. Muth, Opt. Lett. 35, 2088 (2010).

163) S. Arnon, J. Barry and G. Karagiannidis, Advanced Optical Wireless Communication Systems (Cambridge University Press, 2012).

164) H. Gao and H. Zhao, Transport Theor. Stat. 38, 149 (2009).

165) S. Jaruwatanadilok, IEEE J. Sel. Areas Commun. 26, 1620 (2008).

166) W. C. Cox, Simulation, Modeling, and Design of Underwater Optical Communication Systems (North Carolina State University, 2012).

167) J. Huang, Y. Zhang, D. Li and S. Ren, 7th International Conference on Intelligent Human-Machine Systems and Cybernetics, 2015, p. 517.

168) J. Li, Y. Ma, Q. Zhou, B. Zhou and H. Wang, Opt. Eng. 51, 066001 (2012).

169) M. V. Jamali and J. A. Salehi, 4th International Workshop on Optical Wireless Communications (IWOW), 2015, p. 26.

170) X. Yi, Z. Li and Z. Liu, Appl. Opt. 54, 1273 (2015).

171) M. V. Jamali, P. Khorramshahi, A. Tashakori, A. Chizari, S. Shahsavari, S. Abdollahramezani, M. Fazelian, S. Bahrani and J. A. Salehi, Statistical Distribution of Intensity Fluctuations for Underwater Wireless Optical Channels in the Presence of Air Bubbles (2016) pp. 1.

172) D. K. Woolf, Encyclopedia of Ocean Sciences (2001) 352.

173) D. C. Blanchard and A. H. Woodcock, Tellus Dyn. Meteorol. Oceanogr. 9, 145 (1957).

174) X. Zhang, M. Lewis and B. Johnson, Appl. Opt. 37, 6525 (1998).

175) G. E. Davis, J. Opt. Soc. Am. 45, 572 (1955).

176) E. A. Boyle and L. Keigwin, Nature. 330, 35 (1987).

177) V. B. Parr and J. Webster, Technometrics. 7, 1 (1965).

178) D. J. Rogers, J. C. Bienfang, A. Mink, B. J. Hershman, A. Nakassis, X. Tang, L. Ma, D. H. Su, C. J. Williams and C. W. Clark, SPIE Optics + Photonics, 2006, p. 10.

179) J. T. Beatty, J. Overmann, M. T. Lince, A. K. Manske, A. S. Lang, R. E. Blankenship, C. L. Van Dover, T. A. Martinson and F. G. Plumley, Proc. Natl. Acad. Sci. U.S.A. 102, 9306 (2005).

180) J. T. O. Kirk, Light and Photosynthesis in Aquatic Ecosystems (Cambridge University Press, Cambridge, UK, 2011) 3rd ed.

181) M. Lanzagorta, Underwater Communications (Morgan \& Claypool, San Rafael, California, 2013).

182) R. E. Blankenship, Molecular Mechanisms of Photosynthesis (John Wiley \& Sons, 2014).

183) T. Man al, T.-K. Ahn, G. S. Engel, R. E. Blankenship, G. R. Fleming, Y.-C. Cheng, E. L. Read and T. R. Calhoun, Nature. 446, 782 (2007).

184) M. S. Bradley, J. R. Tischler and V. Bulović, Adv. Mater. 17, 1881 (2005).

185) T. Kobayashi, J-aggregates (World Scientific, 2012).

186) C. M. Swenson, C. A. Steed, I. A. De La Rue and R. Q. Fugate, Proc. SPIE, 1997, p. 296.

187) J. A. Simpson, B. L. Hughes and J. F. Muth, IEEE J. Sel. Areas Commun. 30, 964 (2012). 


\section{Authors' biographies}
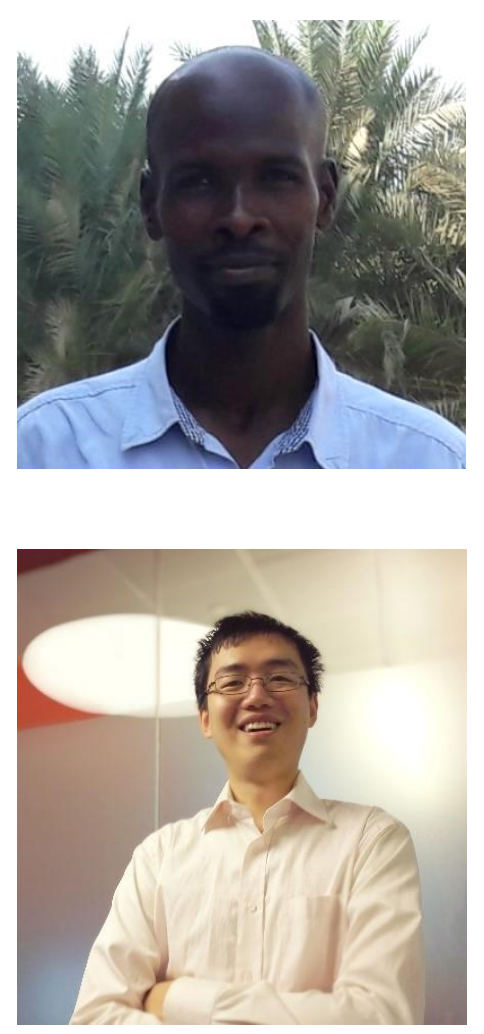

Hassan Makine Oubei is a Ph.D. Student at the Computer, Electrical and Mathematical Sciences and Engineering at KAUST. He received the B.S (2007) and M.S (2010) degree in Electrical Engineering from the City College of New York, and Binghamton University in Binghamton, New York, USA, respectively. His research interest is in the area of underwater wireless optical communications (UWOC) and underwater wireless optical channel modeling. He co-authored over 40 peer reviewed journal and conference papers.

Chao Shen received his B.S. degree in Materials Physics from Fudan University, and the Ph.D. degree in Electrical Engineering from King Abdullah University of Science and Technology, in 2011 and 2017, respectively. He is currently a research consultant at KAUST. He has coauthored over 45 peer-reviewed journal and conference papers. His research interests include III-nitride laser diodes, superluminescent diodes, and micro-LEDs, as well as their applications for solid-state lighting, visible light communications, and photonic integrated circuits.

Abla Kammoun received engineering degree in signal and systems from the Tunisia Polytechnic School, La Marsa, and Master and Ph.D. degree in digital communications from Telecom Paris Tech [then Ecole Nationale Sup erieure des Telecommunications (ENST)]. From June 2010 to April 2012, she was a Postdoctoral Researcher in the TSI Department, Tel' ecom Paris Tech. Then she worked at Supelec at the Alcatel-Lucent Chair on Flexible Radio until December 2013. Currently, she is a research scientist at KAUST working on performance analysis, random matrix theory, and semi-blind channel estimation. She received the SAM 2014 second Prize Best paper award.

Emna Zedini received the Diplome d'Ingenieur degree in telecommunication engineering and the M.Sc. degree from the Ecole Superieure des Communications de Tunis (SUP'COM), Tunis, Tunisia, in 2010 and 2011, respectively. She received the Ph.D. degree in Electrical Engineering from King Abdullah University of Science and Technology (KAUST), Saudi Arabia, in 2016. She joined recently Hamad Bin Khalifa University (HBKU), Doha, Qatar as a postdoctoral researcher. Her research interests include channel modeling and performance analysis of optical wireless communication systems, with current research focusing on underwater optical wireless communication. 

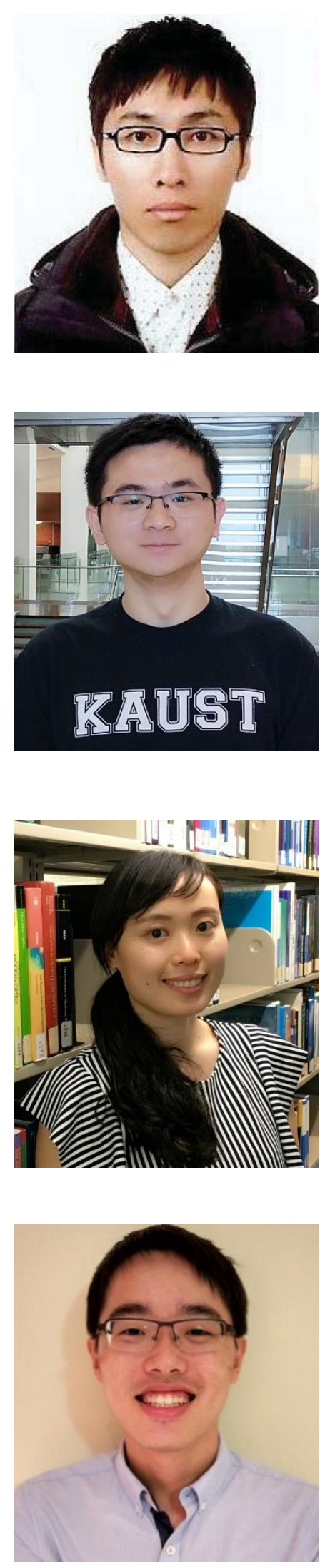

Ki-Hong Park received his B.Sc. degree in Electrical, Electronic, and Radio Engineering from Korea University, Seoul, Korea, in 2005 and his M.S. and $\mathrm{Ph} . \mathrm{D}$. degrees in the School of Electrical Engineering from Korea University, Seoul, Korea, in 2011. Until 2014, he was a postdoctoral fellow and is currently working for a research scientist in the Division of Physical Science and Engineering at King Abdullah University of Science and Technology (KAUST), Thuwal, Saudi Arabia. On-going research project is the design and analysis of optical wireless communication systems.

Xiaobin Sun received his M.S. degree at King Abdullah University of Science and Technology (KAUST), Saudi Arabia, in 2017, and his B.S. degree in physical from University of Science and Technology, Beijing (USTB), China. $\mathrm{He}$ is now continuing his Ph.D. at KAUST. His research focuses on semiconductor Optoelectronics and underwater wireless optical communication.

Guangyu Liu is currently a Research Scientist at Photonics Laboratory (KAUST). She received her Ph.D. in Electrical Engineering at Lehigh University, USA in 2013. Her B.Sc. in Electronic Science and Technology was received with honor at Huazhong University of Science and Technology (HUST), China in 2008. Prior to KAUST, she worked as Process Technology Development Engineer at Intel Corp, USA from 2013-2016. As of April 2018, she has authored/co-authored more than 20 journal papers. Her current research area is III-nitride semiconductor based integrated devices and systems for communication and sensing applications.

Chun Hong Kang is currently a Ph.D. student in Photonics Laboratory at King Abdullah University of Science and Technology (KAUST). He obtained his B. Eng. (2014) and MSc. (2016) in Electrical and Electronics Engineering from Universiti Teknologi PETRONAS, Malaysia. Prior to joining KAUST, he also worked as Graduate Researcher and Teaching Assistant at the Center of Innovative Nanostructures and Nanodevices (COINN), Universiti Teknologi PETRONAS. His research interest includes various III-nitride optoelectronics devices and two-dimensional materials. 

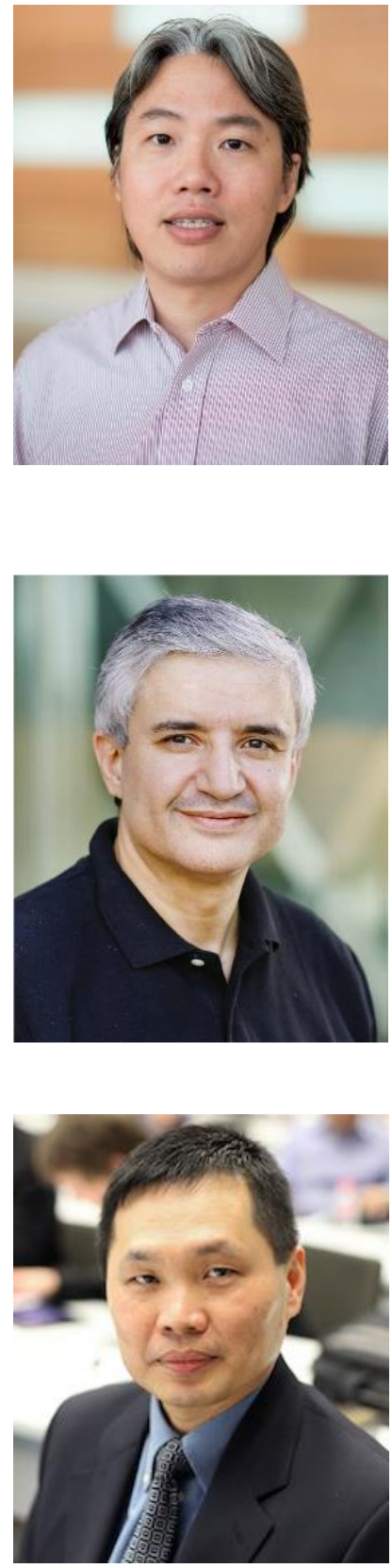

Dr. Tien Khee $\mathrm{Ng}$ is a senior member of IEEE and a senior member of The Optical Society (OSA). He received his Ph.D. (2005) and M.Eng. (2001) from Nanyang Technological University (NTU), Singapore. He was a Test Engineer at Hewlett-Packard Singapore (1997-1998), a member-of-technical-staff with Tinggi Technologies (2004-2006), and a research fellow at NTU until 2009. $\mathrm{He}$ is a senior research scientist with Ooi-group at King Abdullah University of Science and Technology (KAUST), Saudi Arabia. As a co-principalinvestigator responsible for innovation in MBE-grown nanostructures devices, at the KACST Technology-Innovation-Center at KAUST, he realized widebandgap nitride quantum-confined and nanowires structures for addressing efficient light-emitters, optical wireless communications, and energy harvesting.

Professor Alouini was born in Tunis, Tunisia. He received the Ph.D. degree in Electrical Engineering from the California Institute of Technology (Caltech), Pasadena, CA, USA, in 1998. He served as a faculty member in the University of Minnesota, Minneapolis, MN, USA, then in the Texas A\&M University at Qatar, Education City, Doha, Qatar before joining King Abdullah University of Science and Technology (KAUST), Thuwal, Makkah Province, Saudi Arabia as a Professor of Electrical Engineering in 2009. His current research interests include the modeling, design, and performance analysis of wireless communication systems.

Boon S. Ooi is a Professor of Electrical Engineering at KAUST. He received his B.Eng. and Ph.D. in electronics and electrical engineering from the University of Glasgow. His research is concerned with the study of semiconductor lasers, LEDs and photonic integrated circuits for applications in energy efficient lighting and visible light communications. He has served on the editorial board of IEEE Photonics Journal, and on the technical program of IEDM, OFC, CLEO and IPC. Presently, he is the Associate Editor of Optics Express (OSA) and Journal of Nanophotonics (SPIE). He is a Fellow of OSA, SPIE and IoP (UK). 


\section{Figure Captions}

Fig. 1. (Color online) Illustration of various underwater platforms requiring reliable and high speed wireless links.

Fig. 2. (Color online) Schematic of a typical UWOC link. The transmitter is composed of a modulator (M), laser (L), and projection optics (PO) systems. The receiver is made of collection optics (CO), detector (D) and noisy electronics.

Fig. 3. (Color online) Experimental setup for underwater transmission measurements: electrical amplifier (EA), laser diode (LD), variable attenuator (VA), mirror (M1, M2), and avalanche photodetector (APD). (Reprint from ${ }^{30)}$, Copyright 2015 Optical Society of America).

Fig. 4. (Color online) (a) Absorption coefficient of light in water. (b) Transmittance versus transmission distance for 405, 550, 650, and $800 \mathrm{~nm}$ lights. (Reprint from ${ }^{9,66)}$. Copyright 2015 Optical Society of America).

Fig. 5. (Color online) Experimental measurements of the scattering phase functions of various ocean water types and Maalox antacid by Petzold ${ }^{69)}$ and Duntley ${ }^{70)}$. Figure is taken from Ref. ${ }^{72)}$.

Fig. 6. (Color online) Band diagram of various wide bandgap materials. (Reprint from ${ }^{95)}$. Copyright 2015 The Japan Society of Applied Physics).

Fig. 7. (Color online) (a) Schematic illustration of the experimental setup of photon-counting communication system through a $1 \mathrm{~m}$ long water tank by using SPAD (Reprint from ${ }^{118)}$ ). (b) The BER performance of SPAD in a $4 \mathrm{~km}$ long metal pipe at different transmission speed for practical application in downhole monitoring (Reprint from ${ }^{119)}$. Copyright 2014 IEEE Global Communications Conference). (c) The simulated comparison of BER performance between APD and SPAD for UWOC communication system (Reprint from ${ }^{121)}$. Copyright 2016 IEEE Photonics Journal).

Fig. 8. (Color online) (a) Line-of-sight (LOS) link. (b) Diffuse-LOS link. (c,d,e) Non-LOS link. ${ }^{141)}$

Fig. 9. (Color online) Histogram of the measured data along with the exponential-Gamma and exponential log-normal model for fresh water for a bubble level equal to $7.1 \mathrm{~L} / \mathrm{min}$. (Reprint from 47). 2017 IEEE Global Communications Conference).

Fig. 10. (Color online) Salinity gradient $=5 \times 10^{-2} \mathrm{~g} . \mathrm{L}^{-1} \mathrm{~cm}^{-1}, \sigma_{\mathrm{t} \text {,measured }}^{2}=0.0429, \lambda=$ $1.0844, \mathrm{k}=5.1982, \sigma_{\mathrm{t}}^{2}=0.0487$. $\left(\right.$ Reprint from ${ }^{45)}$ )

Fig. 11. (Color online) Histograms of the measured data along with the PDF of various distributions under different temperature gradient levels: (a) $0.05^{\circ} \mathrm{C} \cdot \mathrm{cm}^{-1}$, (b) $0.10{ }^{\circ} \mathrm{C} \cdot \mathrm{cm}^{-1}$, (c) $0.15^{\circ} \mathrm{C} \cdot \mathrm{cm}^{-1}$, and $(\mathrm{d}) 0.20{ }^{\circ} \mathrm{C} \cdot \mathrm{cm}^{-1}$. (Reprint from ${ }^{46)}$ ) 
Table I. Summary of recently achieved UWOC data transmission rates and links distances

\begin{tabular}{|c|c|c|c|c|c|c|}
\hline Authors & $\begin{array}{l}\text { Modulation } \\
\text { Scheme }\end{array}$ & $\begin{array}{c}\text { Transmitter } \\
\text { Type }\end{array}$ & $\begin{array}{l}\text { Photo- } \\
\text { detector }\end{array}$ & $\begin{array}{l}\text { Transmitter } \\
\text { Power }\end{array}$ & $\begin{array}{c}\text { Link } \\
\text { Range }\end{array}$ & Data Rate \\
\hline $\begin{array}{l}\text { K. Nakamura }{ }^{9)} \\
\text { (Uni. of } \\
\text { Yamanashi) } \\
\text { (2015) }\end{array}$ & OFDM & $405 \mathrm{~nm}$ LD & APD & $45 \mathrm{~mW}$ & $4.8 \mathrm{~m}$ & 1.45 Gbps \\
\hline $\begin{array}{l}\text { J. Baghdady }{ }^{38)} \\
\text { (Clemson Uni.) } \\
\text { (2016) }\end{array}$ & OAM-OOK & $445 \mathrm{~nm} \mathrm{LD}$ & APD & $15 \mathrm{~mW}$ & $2.96 \mathrm{~m}$ & $3 \mathrm{Gbps}$ \\
\hline $\begin{array}{l}\text { C. Shen }{ }^{32)} \\
\text { (KAUST) } \\
(\mathbf{2 0 1 6 )}\end{array}$ & OOK & $450 \mathrm{~nm}$ LD & APD & $51.3 \mathrm{~mW}$ & $20 \mathrm{~m}$ & $1.5 \mathrm{Gbps}$ \\
\hline $\begin{array}{l}\text { Y. Huang }{ }^{42)} \\
\text { (National } \\
\text { Taiwan Uni.) } \\
\text { (2017) }\end{array}$ & OFDM & $450 \mathrm{~nm} \mathrm{LD}$ & PIN/APD & $120 \mathrm{~mW}$ & $1.7 \mathrm{~m}$ & $14.8 \mathrm{Gbps}$ \\
\hline $\begin{array}{l}\text { X. Liu }{ }^{43)} \\
\text { (Fudan Uni.) } \\
\text { (2017) }\end{array}$ & OOK & $520 \mathrm{~nm} \mathrm{LD}$ & APD & $19.4 \mathrm{~mW}$ & $34.5 \mathrm{~m}$ & 2.7 Gbps \\
\hline $\begin{array}{l}\text { Y. Chen }{ }^{34)} \\
\text { (Zhejiang Uni.) } \text { (2017) }\end{array}$ & OFDM & $520 \mathrm{~nm} \mathrm{LD}$ & APD & $15 \mathrm{~mW}$ & $21 \mathrm{~m}$ & 5.5 Gbps \\
\hline $\begin{array}{l}\text { P. } \operatorname{Tian}^{33)} \\
\text { (Fudan Uni.) } \\
\text { (2017) }\end{array}$ & OOK & $\begin{array}{l}450 \mathrm{~nm} \mu- \\
\quad \text { LED }\end{array}$ & PIN/APD & $1.5 \mathrm{~mW}$ & $5.4 \mathrm{~m}$ & $200 \mathrm{Mbps}$ \\
\hline $\begin{array}{l}\text { T. C. } \mathrm{Wu}^{10)} \\
(\mathbf{N T U )} \\
(\mathbf{2 0 1 7})\end{array}$ & OFDM & $450 \mathrm{~nm} \mathrm{LD}$ & PIN & $47 \mathrm{~mW}$ & $1.7 \mathrm{~m}$ & 12.4 Gbps \\
\hline $\begin{array}{l}\text { M. Kong }{ }^{11)} \\
\text { (Zhejiang Uni.) } \\
\text { (2017) }\end{array}$ & OFDM & $\begin{array}{c}\text { RGB- } \\
\text { WDM LD }\end{array}$ & APD & $15 / 35 \mathrm{~mW}$ & $10 \mathrm{~m}$ & $9.51 \mathrm{Gbps}$ \\
\hline
\end{tabular}


Table II. Summary of solar-blind photodetector based on wide bandgap materials

\begin{tabular}{|c|c|c|c|c|c|c|}
\hline \multirow[t]{2}{*}{$\begin{array}{l}\text { Authors } \\
\text { (Year) }\end{array}$} & \multirow[t]{2}{*}{ PD type } & \multirow[t]{2}{*}{$\begin{array}{c}\lambda_{\text {range or }} \\
\lambda_{\text {peak }}\end{array}$} & \multirow[t]{2}{*}{$R(\mathbf{A} / \mathbf{W})$} & \multicolumn{2}{|c|}{$\begin{array}{l}\text { Transient } \\
\text { response }\end{array}$} & \multirow[t]{2}{*}{ Bandwidth } \\
\hline & & & & $t_{\text {rise }}$ & $t_{\text {fall }}$ & \\
\hline $\begin{array}{l}\text { J. C. Carrano } \\
\text { (U6) } \\
\text { (1998) }\end{array}$ & GaN MSM & $267 \mathrm{~nm}$ & - & $28 \mathrm{ps}$ & - & $3.5 \mathrm{GHz}$ \\
\hline $\begin{array}{l}\text { J. C. Carrano } \\
\text { (UT) } \\
\text { (UTustin) } \\
\text { (1998) }\end{array}$ & GaN PIN & $267 \mathrm{~nm}$ & - & $43 \mathrm{ps}$ & - & $1.4 \mathrm{GHz}$ \\
\hline $\begin{array}{l}\text { A. Osinsky }{ }^{97)} \\
\text { (APA Opt Inc) } \\
\text { (1998) }\end{array}$ & AlGaN MSM & $240-290 \mathrm{~nm}$ & 0.07 & - & $1.6 \mu \mathrm{s}$ & - \\
\hline $\begin{array}{l}\text { C. Pernot }{ }^{98)} \\
\text { (Univ. Montpellier II) } \\
(\mathbf{2 0 0 0 )}\end{array}$ & $\begin{array}{c}\text { GaN/AlGaN } \\
\text { PIN }\end{array}$ & $270 \mathrm{~nm}$ & 0.012 & - & $14 \mu \mathrm{s}$ & - \\
\hline $\begin{array}{l}\text { T. Tut } \\
\text { (Bilkent Univ.) } \\
(\mathbf{2 0 0 5 )}\end{array}$ & $\begin{array}{c}\text { AlGaN } \\
\text { Schottky diode }\end{array}$ & $256 \mathrm{~nm}$ & 0.147 & $26 \mathrm{ps}$ & - & $4.1 \mathrm{GHz}$ \\
\hline $\begin{array}{l}\text { T. Tut }{ }^{100)} \\
\text { (Bilkent Univ.) } \\
(\mathbf{2 0 0 8 )}\end{array}$ & AlGaN PIN & $266 \mathrm{~nm}$ & 0.093 & - & - & - \\
\hline $\begin{array}{l}\text { S. Rathkanthiwar }{ }^{101)} \\
\text { (Indian Inst. Sci.) } \\
\text { (2017) }\end{array}$ & AlGaN MSM & $245-190 \mathrm{~nm}$ & 5 & - & - & - \\
\hline $\begin{array}{l}\text { A. Soltani }{ }^{102)} \\
\text { (Raytheon } \\
\text { Tech.) } \\
\text { (2008) }\end{array}$ & c-BN MSM & $180 \mathrm{~nm}$ & 0.032 & - & - & - \\
\hline $\begin{array}{l}\text { H. Srour }{ }^{103)} \\
\text { (Univ. Lorraine \& } \\
\text { Supelec) } \\
\text { (2011) }\end{array}$ & $\begin{array}{c}\text { BGaN/GaN SL } \\
\text { MSM }\end{array}$ & $375 \mathrm{~nm}$ & 0.03 & $15 \mathrm{~ns}$ & $44 \mathrm{~ns}$ & - \\
\hline $\begin{array}{l}\text { T. C. Doan }{ }^{104)} \\
\text { (Texas Tech Univ.) } \\
\text { (2016) }\end{array}$ & h-BN MSM & $217 \mathrm{~nm}$ & - & - & - & - \\
\hline $\begin{array}{l}\text { C. Soci }{ }^{105)} \\
\text { (UCSD) } \\
(\mathbf{2 0 0 7 )}\end{array}$ & $\mathrm{ZnO} \mathrm{NW}$ MSM & $250-390 \mathrm{~nm}$ & - & - & $20 \mathrm{~ns}$ & - \\
\hline $\begin{array}{l}\text { M. Nakano }{ }^{106)} \\
\text { (Tohoku Univ.) } \\
\text { (2008) }\end{array}$ & $\begin{array}{l}\text { ZnO Schottky } \\
\text { diode }\end{array}$ & $240-380 \mathrm{~nm}$ & 0.3 & - & - & - \\
\hline $\begin{array}{l}\text { J. Du }{ }^{107)} \\
\text { (China Univ. of }\end{array}$ & $\beta-\mathrm{Ga}_{2} \mathrm{O}_{3} \mathrm{NW}$ & $231 \mathrm{~nm}$ & 377 & $0.8 \mathrm{~ns}$ & $12 \mathrm{~ns}$ & - \\
\hline
\end{tabular}


Geosciences)

(2016)

A. Singh Pratiyush ${ }^{108)}$ (Indian Inst. Sci.) (2017)

B. Zhao ${ }^{109)}$ (Fudan Univ.) (2017)

A. BenMoussa ${ }^{88)}$ (STCE) (2009)

L. Wang ${ }^{110)}$

(CAS)

(2009)

Y. N. Hou ${ }^{111)}$

(CAS)

(2011)

Y. D. Zhu ${ }^{112)}$

(Wuhan Univ.)

(2012)

Y. Guo ${ }^{113)}$

(The Univ. of Tokyo)

(2015)
MSM

$\begin{array}{lllll}\beta-\mathrm{Ga}_{2} \mathrm{O}_{3} \mathrm{MSM} & 236 \mathrm{~nm} & 1.8 & 3.33 \mathrm{~s} & 0.4 \mathrm{~s}\end{array}$

$\mathrm{ZnO}-\mathrm{Ga}_{2} \mathrm{O}_{3}$

Core-shell wire

$251 \mathrm{~nm}$

$9.7 \mathrm{e}-3$

100

$\mu \mathrm{s} \quad \mu \mathrm{s}$

Diamond MSM $\quad 210 \mathrm{~nm} \quad 0.048$

$\begin{array}{lllll}\text { MgZnO MSM } & 268 \mathrm{~nm} & 0.016 & 10 \mathrm{~ns} & 150 \\ & & & n s\end{array}$

$\mathrm{MgZnO} / \mathrm{Si} \mathrm{PN}$

250-300 nm

1

$\sim \mathrm{s} \quad 4 \mathrm{~s}$

$\mathrm{MgZnO} / \mathrm{ZnO}$

MSM

$300 \mathrm{~nm}$

0.45

$4 \mathrm{~s}$

$4 \mathrm{~s}$

Perovskite MSM

200-400nm

7.85

$0.2 \mu \mathrm{s} \quad 0.7 \mu \mathrm{s}$ 
Table III. Performance comparison of different scheme of single-photon detectors

\begin{tabular}{|c|c|c|c|c|c|c|}
\hline Authors & $\begin{array}{l}\text { Type of } \\
\text { Detector }\end{array}$ & $\begin{array}{l}\text { Operation } \\
\text { Temperature } \\
\text { (K) }\end{array}$ & $\begin{array}{l}\text { Spectral } \\
\text { Range }\end{array}$ & $\begin{array}{l}\text { Maximum } \\
\text { Count Rate, } \\
\text { D }\end{array}$ & 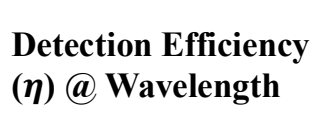 & $\begin{array}{l}\text { Timing } \\
\text { Jitter }(\Delta t)\end{array}$ \\
\hline $\begin{array}{l}\text { Hamamatsu } \\
\text { (Commercial) } \\
\text { (2009) }\end{array}$ & PMT & 300 & $\begin{array}{l}\text { Visible to } \\
\text { NIR }\end{array}$ & $10 \mathrm{MHz}$ & 40\%@500 nm & $300 \mathrm{ps}$ \\
\hline $\begin{array}{l}\text { Thomas et al. }{ }^{132)} \\
\text { (Cambridge) } \\
\text { (2010) }\end{array}$ & Si SPAD & 250 & Visible & $16 \mathrm{MHz}$ & 74\%@600 nm & - \\
\hline $\begin{array}{l}\text { Ghioni et al. }{ }^{133)} \\
\text { (Politecnicodi } \\
\text { Milano) } \\
\text { (2009) }\end{array}$ & Si SPAD & 78 & Visible & $10 \mathrm{MHz}$ & $\begin{array}{l}\text { 42\%@7 } 780 \mathrm{~nm} \\
\sim 34 \% @ 850 \mathrm{~nm}\end{array}$ & $35 \mathrm{ps}$ \\
\hline $\begin{array}{l}\text { Blakesley et al. }{ }^{134)} \\
\text { (Toshiba Research) } \\
\text { (2005) }\end{array}$ & $\begin{array}{l}\text { QD } \\
\text { Resonant } \\
\text { Tunnel } \\
\text { Diode }\end{array}$ & 4 & Visible & $250 \mathrm{kHZ}$ & 12\%@ $550 \mathrm{~nm}$ & $150 \mathrm{~ns}$ \\
\hline $\begin{array}{l}\text { Verevkin et al. }{ }^{124)} \\
\text { (Rochester) } \\
\text { (2002) }\end{array}$ & NbN SSPD & 4.2 & $\begin{array}{l}\text { Visible to } \\
\text { IR }\end{array}$ & $10 \mathrm{GHz}$ & $\begin{array}{l}\sim 10 \% @ 405 \mathrm{~nm} \\
\sim 5 \% @ 1550 \mathrm{~nm}\end{array}$ & $35 \mathrm{ps}$ \\
\hline $\begin{array}{l}\text { Verma et al. }{ }^{126)} \\
\text { (NIST, Boulder) } \\
\text { (2015) }\end{array}$ & $\begin{array}{l}\text { MoSi } \\
\text { SNSPD }\end{array}$ & 0.7 & IR & $10 \mathrm{MHz}$ & >87\%@1542 nm & $76 \mathrm{ps}$ \\
\hline $\begin{array}{l}\text { Slichter et al. }{ }^{127)} \\
\text { (NIST, Boulder) } \\
\text { (2017) }\end{array}$ & $\begin{array}{l}\text { MoSi } \\
\text { SNSPD }\end{array}$ & 3.2 & UV & $0.2 \mathrm{MHz}$ & 76\%@315 nm & $11 \mathrm{~ns}$ \\
\hline
\end{tabular}


Table IV. Performance of achieved data rates for NLOS/Diffuse-LOS communications

\begin{tabular}{|c|c|c|c|c|c|c|}
\hline Authors & $\begin{array}{l}\text { Modulation } \\
\text { Scheme }\end{array}$ & Light Source & $\begin{array}{l}\text { Photo- } \\
\text { detector }\end{array}$ & $\begin{array}{c}\text { Transmission } \\
\text { Power }\end{array}$ & $\begin{array}{l}\text { Channel } \\
\text { Length }\end{array}$ & $\begin{array}{l}\text { Data } \\
\text { Rate }\end{array}$ \\
\hline $\begin{array}{l}\text { M. Geller }{ }^{146)} \\
\text { (U.S. Dept. } \\
\text { of the Navy) } \\
\text { (1985) }\end{array}$ & PPM & $\begin{array}{c}253 \mathrm{~nm} \mathrm{Hg}-\mathrm{Ar} \\
\text { lamp }\end{array}$ & PMT & $5 \mathrm{~W}$ & $0.5 \mathrm{~km}$ & $10 \mathrm{kbps}$ \\
\hline $\begin{array}{l}\text { J. J. Puschell }{ }^{145)} \\
\text { (TITAN Syst.) } \\
\text { (1990) }\end{array}$ & PPM & $\begin{array}{c}265 \mathrm{~nm} \mathrm{Hg}-\mathrm{Xe} \\
\text { lamp }\end{array}$ & PMT & $25 \mathrm{~W}$ & $1.6 \mathrm{~km}$ & $1.2 \mathrm{Mbps}$ \\
\hline $\begin{array}{l}\text { D. Han } \\
\text { (SIOM, CAS) } \\
\text { (2012) }\end{array}$ & OOK/PPM & $265 \mathrm{~nm}$ LED & PMT & $43 \mathrm{~mW}$ & $100 \mathrm{~m}$ & $2.4 \mathrm{kbps}$ \\
\hline $\begin{array}{l}\text { Boon S. Ooi }{ }^{141)} \\
\text { (KAUST) } \\
\text { (2017) }\end{array}$ & OFDM & 294 nm LED & APD & $190 \mu \mathrm{W}$ & $8 \mathrm{~cm}$ & $71 \mathrm{Mbps}$ \\
\hline
\end{tabular}


Table V. Typical values of absorption, scattering and attenuation coefficients for the different ocean water types ${ }^{25,159)}$

\begin{tabular}{|c|c|c|c|}
\hline Water type & $\mathbf{a}(\boldsymbol{\lambda})(/ \mathbf{m})$ & $\mathbf{b}(\lambda)(/ \mathbf{m})$ & $\mathbf{c}(\boldsymbol{\lambda})(/ \mathbf{m})$ \\
\hline Pure sea & 0.0405 & 0.0025 & 0.043 \\
\hline Clear ocean & 0.114 & 0.037 & 0.151 \\
\hline Coastal ocean & 0.179 & 0.219 & 0.298 \\
\hline Turbid harbor & 0.266 & 1.824 & 2.19 \\
\hline
\end{tabular}


Table VI. Different salinity values used to create salinity gradient in the water channel ${ }^{45)}$

\begin{tabular}{|c|c|c|c|}
\hline $\begin{array}{c}\text { Bucket 1 salinity } \\
(\mathbf{g} / \mathbf{L})\end{array}$ & $\begin{array}{c}\text { Bucket 2 salinity } \\
(\mathbf{g} / \mathbf{L})\end{array}$ & $\begin{array}{c}\text { Channel gradient } \\
\left(\mathbf{g} . \mathbf{L}^{-\mathbf{1}} \mathbf{. m}^{-\mathbf{1}}\right)\end{array}$ & $\begin{array}{c}\text { Mean salinity } \\
(\mathbf{g} / \mathbf{L})\end{array}$ \\
\hline 27.5 & 22.5 & 0.05 & \multirow{2}{*}{25} \\
\hline 30.0 & 20.0 & 0.10 & \\
\hline 32.5 & 17.5 & 0.15 & \\
\hline 35.0 & 15.0 & 0.20 & \\
\hline
\end{tabular}

